\title{
Testing for Periodic Integration with a changing mean*
}

\author{
Tomás del Barrio \\ University of the Balearic Islands
}

\author{
Mariam Camarero \\ Universitat Jaume I
}

Cecilio Tamarit

University of Valencia

December 14, 2016

\begin{abstract}
In this paper we extend the test of periodic integration proposed by Boswijk and Franses (1996) allowing for a change in the mean. We provide the asymptotic distribution and show that is the square of the distribution obtained by Perron and Vogelsang (1992a,1992b). In a Monte-Carlo experiment we show a good behaviour of the test in terms of size and power. Finally we have illustrated the use of the test in an empirical application to the case of external imbalances in the eurozone.
\end{abstract}

JEL: C12, C22

Keywords: periodic integration, change in the mean, trade balance

\footnotetext{
${ }^{*}$ We thank Denise R. Osborn, A. M. Robert Taylor, A. Banerjee and two anonymous referees for helpful and constructive comments on a previous version of this paper. The authors gratefully acknowledge the financial support from MINECO (Projects ECO2014-51759-REDT and ECO2014-58991-C3-3-R), the Generalitat Valenciana (PROMETEOII/2014/053 project) and the European Commission Lifelong Learning Program (Project 542434-LLP-1-2013-1-ES-AJM-CL ). The usual disclaimer applies.
} 


\section{Motivation}

Seasonality is a phenomenon that has not received sufficient attention in the economic literature in general. The standard treatment is either to assume that the seasonality that appears in the time series is deterministic or, alternatively, to use a method to remove the seasonal component of the variables and estimate the models using seasonally-adjusted variables.

When it is assumed that the seasonality is deterministic, the normal practice is to use seasonal dummies, which implicitly assumes that seasonality is a deterministic phenomenon. The methods of seasonal adjustment commonly used are variants of the X-11 procedure (X-12 ARIMA and X-13 ARIMA) of the U.S. Census Bureau, and also the ARIMA model based procedures implemented in the TRAMO-SEATS program developed at the Bank of Spain. However, these procedures usually corrupt the stochastic structure of the variables and can induce non-invertible moving average processes in the filtered series, a fact that invalidates inference in the context of non-stationary variables (see Maravall (1993), Ghysels (1990) and Ghysels and Perron (1993)).

There are two alternative methods that have been applied in the literature to deal with nonstationary seasonal time series. The first possibility is Seasonal Integration (SI), see for example Hylleberg et al (1990), Hylleberg (1995) and Rodrigues and Taylor (2007). The second method is Periodic Integration (PI). The advantages of using PI instead of $S I$ arise both from an economic and an econometric point of view. Periodic Integration is more attractive than SI because PI can originate naturally from the application of economic theory when the underlying economic driving forces, such as preferences or technologies, vary seasonally ${ }^{1}$. From an econometric perspective and according to Osborn (1991) and Franses (1994), PI implies that the seasons of the year are cointegrated with each other. This ensures a long-run link between the patterns associated with the various seasons. In order to test the null of PI, Franses (1994) proposes the use of the Johansen (1995) cointegration procedure multivariate vector of seasons representation of a seasonal time series. Boswijk and Franses $(1995,1996)$ proposed a Likelihood Ratio test to test the null of PI and finally del Barrio Castro and Osborn (2011) propose non-parametric tests for the null of $P I$.

When testing form non stationary behavior in time series, it is important to take into account the presence of breaks in the deterministic part of the process. Since the influential work of Perron (1989), an important part of the unit roots literature has been devoted to the development of unit root tests which allow for breaks; see for instance, Perron (2006) and Choi (2015) for an overview. In the seasonal context, developments have been mostly centered in $S I$ approach, that is, seasonal units roots tests allowing for breaks in the deterministic part, see among others Franses and Vogelsang (1998), Harvey, Leybourne and Newbold (2002), Hassler and Rodrigues (2004) and Nunes and Rodrigues (2011). But in the case of PI integration, only Maekawa (1997) considers structural breaks in the case of the Boswijk and Franses (1995) test for PI for a Periodic Autoregressive process of order one, paying attention to the specifications proposed by Perron (1989) for the deterministic part. Maekawa (1997) only considers a periodic autoregressive process of order one and the proof of the

\footnotetext{
${ }^{1}$ See for example Gersovitz and McKinnon (1978), Osborn (1988) and Hansen and Sargent (1993).
} 
analytical results it is not reported in the paper. Furthermore, he did not pay attention to the case of a changing mean considered by Perron(1990) and Perron and Vogelsang (1992a).

In this paper we extend the Boswijk and Franses (1996) test allowing for a changing mean for a general periodic autoregressive process of order $p P A R(p)$. We illustrate the use of this new test analyzing the current account sustainability. A salient feature scarcely studied in the literature is that trade variables are examples of magnitudes with a seasonal pattern. However, just a few countries have data available in their official statistics that has not been seasonally adjusted. In particular, the researchers have at their disposal only data for thirteen OECD countries ${ }^{2}$. The long-run relationship between exports and imports has been previously studied, among others, by Husted (1992), Arize (2002) or by Narayan and Narayan (2005) using cointegration techniques. However, excepting del Barrio Castro, Camarero and Tamarit (2015), to the best of our knowledge no empirical paper has taken into account the presence of seasonal or periodic non-stationary components. Moreover, none has analyzed the possibility of instabilities in this setting. Our aim in this paper is to fill this gap using the European monetary integration process as a case study. Indeed, the process of monetary integration in Europe constitutes a natural experiment to analyze the existence of instabilities in the long-run relationships. A simple way to deal with the instability of the relationships between elements of the current account, without assuming the existence of unobserved components, is to model explicitly the seasonal behavior of the time series. We show how the results depend critically on the consideration of a changing mean in the series of the euro area countries considered in the analysis.

The rest of the paper is organized as follows. Section 2 presents our test for $P I$ allowing for a changing mean, where the test is derived and the analytical and Monte-Carlo results are reported. In Section 3 we present the empirical application to the case of the current account sustainability in some selected Eurozone countries. Finally, the last Section concludes.

\section{The LR test for periodic Integration allowing for a changing mean}

In order to explicitly recognize the role of seasonality, we represent a univariate time series as $y_{s \tau}$, where the first subscript refers to the season $(s)$ and the second subscript to the year $(\tau)$, as we have quarterly data $s=1,2,3,4^{3}$. The Boswijk and Franses (1996) test is based in the Periodic Autoregressive model $P A R(p)$

$$
y_{s \tau}=\alpha_{s}+\phi_{1 s} y_{s-1, \tau}+\phi_{2 s} y_{s-2, \tau}+\cdots+\phi_{p s} y_{s-p, \tau}+e_{s \tau}, \quad s=1,2,3,4
$$

where $e_{s \tau}$ is white noise and $\alpha_{s}$ are the seasonal intercepts. Under the null of $P I(1)$ could be rewrite as

$$
\begin{aligned}
\left(y_{s \tau}-\varphi_{s} y_{s-1, \tau}\right)= & \alpha_{s}^{*}+\psi_{1 s}\left(y_{s-1, \tau}-\varphi_{s-1} y_{s-2, \tau}\right)+\cdots+ \\
& \psi_{p-1, s}\left(y_{s-p+1, \tau}-\varphi_{s-p+1} y_{s-p, \tau}\right)+e_{s \tau}
\end{aligned}
$$

where $\prod_{s=1}^{4} \varphi_{s}=1$, with the quasi-difference $y_{s \tau}-\varphi_{s} y_{s-1, \tau}$ being stationary.

\footnotetext{
${ }^{2}$ These countries are: Australia, Canada, Denmark, Sweden, the UK, Norway, Switzerland, Japan, France, Italy, the Netherlands, Finland and Spain.

${ }^{3}$ For simplicity of exposition, we assume that data are available for precisely $N$ years, so that the total sample size is $T=4 N$. Note that, throughout the paper, it is understood that $y_{s-k, \tau}=y_{4-s+k, \tau-1}$ for $s-k \leq 0$.
} 
Boswijk and Franses (1996) analyze the distribution of the Likelihood Ratio test statistic for the null of $P I \prod_{s=1}^{S} \varphi_{s}=1$ versus the alternative of $\prod_{s=1}^{S} \varphi_{s}<1$, with this statistic defined by

$$
L R=T \ln \left(\frac{R S S_{0}}{R S S_{1}}\right)
$$

where $R S S_{0}$ and $R S S_{1}$ denote the residual sum of squares under the null hypothesis of the restricted model (2) and from the unrestricted form (1), respectively. Boswijk and Franses (1996) show that under the null hypothesis of a $P I(1)$ or $I(1)$ process, the $L R$ statistic has the same asymptotic distribution as the squared Dickey-Fuller $t$-statistic for a conventional (nonperiodic) $I(1)$ process.

In this section we extend the $P I$ test proposed by Boswijk and Franses (1996) to the case where we allow for a change in the mean in the deterministic part of the periodic autoregressive process. In particular we consider the periodic counterpart of the case proposed by Perron(1990) and Perron and Vogelsang (1992a) under the null hypothesis of PI. Maekawa (1997) considers structural breaks in a periodically integrated process but he only pays attention to the PAR(1) model and does not contemplate the following model:

$$
y_{s \tau}=\gamma_{s} D(N B)_{s \tau}+\varphi_{s} y_{s-1, \tau}+u_{s \tau}
$$

with:

$$
\begin{aligned}
s & =1,2,3,4 \tau=1,2,3, \ldots, N \\
D(N B)_{s \tau} & =1 \text { if } \tau=N_{B}+1 \text { otherwise } 0 \\
D U_{s \tau} & =1 \text { if } \tau>N_{B} \text { otherwise } 0 \\
\prod_{s=1}^{S} \varphi_{s} & =1 \\
\left(1-\psi_{1 s} L-\psi_{2 s} L^{2}-\cdots-\psi_{p-1, s} L^{p-1}\right) u_{s \tau} & =\varepsilon_{s \tau}
\end{aligned}
$$

where $N_{B}\left(1<N_{B}<N\right)$ is the date of break and we assume that $N_{B}=\lambda N$, where $\lambda$ is the fraction of break. We define $D U_{s \tau}$ bellow (4) but it will be used latter in (10) and (9). As Boswijk and Franses (1996) and Ghysels and Osborn (2001) pointed out the key to explore the long run properties of $P I$ processes is the vector of quarters (vector moving-average $(V M A))$ representation:

$$
\begin{aligned}
& Y_{\tau}-Y_{\tau-1}=\left(\Theta_{0}+\Theta_{1} B\right) \Psi(B)^{-1} E_{\tau} \\
& \text { with : } \\
& Y_{\tau}=\left[\begin{array}{llll}
y_{1 \tau} & y_{2 \tau} & y_{3 \tau} & y_{4 \tau}
\end{array}\right]^{\prime} \quad E_{\tau}=\left[\begin{array}{llll}
\varepsilon_{1 \tau} & \varepsilon_{2 \tau} & \varepsilon_{3 \tau} & \varepsilon_{4 \tau}
\end{array}\right]^{\prime} \\
& \Theta_{0}=\left[\begin{array}{cccc}
1 & 0 & 0 & 0 \\
\varphi_{2} & 1 & 0 & 0 \\
\varphi_{2} \varphi_{3} & \varphi_{3} & 1 & 0 \\
\varphi_{2} \varphi_{3} \varphi_{4} & \varphi_{3} \varphi_{4} & \varphi_{4} & 1
\end{array}\right] \quad \Theta_{1}=\left[\begin{array}{cccc}
0 & \varphi_{3} \varphi_{4} \varphi_{1} & \varphi_{4} \varphi_{1} & \varphi_{1} \\
0 & 0 & \varphi_{4} \varphi_{1} \varphi_{2} & \varphi_{1} \varphi_{2} \\
0 & 0 & 0 & \varphi_{1} \varphi_{2} \varphi_{3} \\
0 & 0 & 0 & 0
\end{array}\right]
\end{aligned}
$$


where $B$ is the annual lag operator. Following the lines of Boswijk and Franses (1996) from (5) it is possible to write:

$$
Y_{\tau}=Y_{0}+\mathbf{a b}^{\prime} \Psi(1)^{-1} \sum_{j=1}^{\tau} E_{j}+C^{*}(L) E_{\tau}
$$

with:

$$
\mathbf{C}(1)=\left(\Theta_{0}+\Theta_{1}\right)=\mathbf{a b}^{\prime}
$$

where

$$
\begin{aligned}
& \mathbf{a}=\left[\begin{array}{llll}
1 & \varphi_{2} & \varphi_{2} \varphi_{3} & \varphi_{2} \varphi_{3} \varphi_{4}
\end{array}\right]^{\prime}, \\
& \mathbf{b}=\left[\begin{array}{llll}
1 & \varphi_{1} \varphi_{3} \varphi_{4} & \varphi_{1} \varphi_{4} & \varphi_{1}
\end{array}\right]^{\prime} .
\end{aligned}
$$

which is the common trend representation of the $P I$ process without considering deterministic terms. To obtain a equivalent representation to our case we only have to replace $E_{\tau}$ in $(6)$ by $\left(\gamma D(N B)_{\tau}+E_{\tau}\right)$, where $\gamma=\left[\begin{array}{llll}\gamma_{1} & \gamma_{2} & \gamma_{3} & \gamma_{4}\end{array}\right]^{\prime}$ and $D(N B)_{\tau}$ is the $4 \times 1$ vector associated to $D(N B)_{s \tau}$. Hence after some rewriting we have:

$$
\begin{aligned}
Y_{\tau} & =Y_{0}+\mathbf{a b}^{\prime} \Psi(1)^{-1} \gamma D U_{\tau}+C^{*}(1) \gamma D(N B)_{\tau}+X_{\tau} \\
\text { with } & : \\
X_{\tau} & =\mathbf{a b}^{\prime} \Psi(1)^{-1} \sum_{j=1}^{\tau} E_{j}+C^{*}(L) E_{\tau}
\end{aligned}
$$

Note that in the previous expression the term $C^{*}(1) \gamma D(N B)_{\tau}$ plays a role equivalent to the correction added by Perron and Vogelsang $(1992 \mathrm{a}, 1992 \mathrm{~b})$ to the initial analysis developed by Perron (1990) when testing for unit roots with a changing mean. Finally $D U_{\tau}$ is the $4 \times 1$ vector associated to $D U_{s \tau}$.

Our extension of the test for $P I$ allows for the presence of structural breaks in the deterministic part, and also uses a Likelihood Ratio test, where the unrestricted model is as follows:

$$
\begin{aligned}
& \tilde{y}_{s \tau}=y_{s \tau}-\hat{\mu}_{s}-\hat{\gamma}_{s}^{*} D U_{s \tau} \\
& \tilde{y}_{s \tau}=\sum_{j=0}^{p} \omega_{j s} D(N B)_{s-j, \tau}+\sum_{j=1}^{p} \phi_{j s} \tilde{y}_{s-j, \tau}+\varepsilon_{s \tau}
\end{aligned}
$$

that is used to obtain the unrestricted residual sum of squares $\mathbf{R S S}_{1}$. And our restricted model:

$$
\tilde{y}_{s \tau}=\varphi_{s-1} \tilde{y}_{s-1, \tau}+\sum_{j=0}^{p-1} \omega_{j s} D(N B)_{s-j, \tau}+\sum_{j=1}^{p-1} \psi_{j s}\left(\tilde{y}_{s-j, \tau}-\varphi_{s-j} \tilde{y}_{s-j-1, \tau}\right)+\varepsilon_{s \tau}
$$

where $\tilde{y}_{s \tau}$ is defined as in (10) and we have imposed the restriction $\varphi_{1} \varphi_{2} \varphi_{3} \varphi_{4}=1$; however $\psi_{j s}$ is unrestricted. This 
model is used to obtain the restricted residual sum of squares $\mathbf{R S S}_{0}$ We estimate model (11) using nonlinear least squares.

To test the null of $\varphi_{1} \varphi_{2} \varphi_{3} \varphi_{4}=1$ against $\varphi_{1} \varphi_{2} \varphi_{3} \varphi_{4}<1$ we use the following the Likelihood Ratio test (as in Boswijk and Franses (1996)):

$$
L R_{i o}(\lambda)=N \ln \left(\mathbf{R S S}_{0} / \mathbf{R S S}_{1}\right)
$$

In the following proposition we present the distribution of the test.

Proposition 1 Under the null hypothesis of PI the likelihood ratio test statistic (12) obtained from (10)/(11) has the following distribution:

$$
\begin{aligned}
L R_{\text {io }}(\lambda) \Rightarrow & {[D E(\lambda)]^{-1}([N U(\lambda)])^{2} } \\
\text { where }: & \\
{[N U(\lambda)]=} & \int_{0}^{1} w(r) d w(r)-\lambda^{-1} w(\lambda) \int_{0}^{\lambda} w(r) d r+ \\
& +(1-\lambda)^{-1}[w(1)-w(\lambda)] \int_{\lambda}^{1} w(r) d r \\
{[D E(\lambda)]=} & \int_{0}^{1}[w(r)]^{2} d r-\lambda^{-1}\left[\int_{1}^{\lambda} w(r) d r\right]^{2} \\
& -(1-\lambda)\left[\int_{\lambda}^{1} w(r) d r\right]^{2}
\end{aligned}
$$

Note that the result (13) is the square of the distribution obtained by Perron and Vogelsang (1992a,1992b).

Remark 2 Following Berenguer-Rico and Carrion-i-Silvestre (2011), Zivot and Andrews (1992), Gregory and Hansen (1996) and Perron (1997) based on the results of Proposition 1 it is possible to establish for $L R_{i o}^{*}=\sup _{\lambda \in \Lambda}: L R_{i o}(\lambda)$ :

$$
L R_{i o}^{*} \Rightarrow \sup _{\lambda \in \Lambda}\left\{[D E(\lambda)]^{-1}([N U(\lambda)])^{2}\right\}
$$

where $\Lambda$ is a closed subset of the interval $(0,1)$.

Remark 2, states that using the supremum (sup) it is possible to obtain a test that does not depend on $\lambda$ and hence it is possible to use the critical values reported in table 1 of Perron and Vogelsang (1992b). Finally in the case of (13) the critical values to use are those reported in Perron (1990) table 4.

Boswijk and Franses (1996) also proposed a F-type statistic $F_{p e r}$ to test the null of non periodic variation in the coefficients of (1) $H_{0}: \phi_{j s}=\phi_{j}$ for $j=1, \cdots p$. We also use in our empirical application section a F-type test but in our case to test the null hypothesis of non periodic variation in the coefficients in model (10). Also in the empirical section the order $p$ of the models (10)/(11) will be determined using the $A I C$ and $B I C$ criteria following the recommendations of Franses and Paap (2004), with $p=5$ as the maximum value. 
In table 1.a we report the empirical quantiles of the $L R_{i o}(\lambda)$ test based on 20.000 replications and for a sample size of $\tau=1000$ with $S=4$. For $\lambda=0.2,0.3,0.4,0.5,0.6,0.7$ and 0.8 . It is clear that the quantiles associated to (13) are equivalent to the square of the quantiles reported in Perron (1988).

In order to analyze the size and power performance of the $L R_{i o}(\lambda)$ test we run a small monte-carlo experiment based on the following data generating process:

$$
\begin{aligned}
y_{s \tau} & =\varphi_{s} y_{s-1, \tau}+u_{s \tau} \quad s=1,2,3,4 \\
\text { with } & : \\
\text { a) } \varphi_{1} & =0.9 \quad \varphi_{2}=1 \quad \varphi_{3}=1.25 \quad \varphi_{4}=1 /\left(\varphi_{1} \varphi_{2} \varphi_{3}\right) \\
\text { b) } \varphi_{1} & =0.9 \quad \varphi_{2}=1 \quad \varphi_{3}=1.25 \quad \varphi_{4}=0.8 /\left(\varphi_{1} \varphi_{2} \varphi_{3}\right) \\
\text { c) } \varphi_{1} & =0.9 \quad \varphi_{2}=1 \quad \varphi_{3}=1.25 \quad \varphi_{4}=0.5 /\left(\varphi_{1} \varphi_{2} \varphi_{3}\right)
\end{aligned}
$$

with the combination of parameters $a$ ) we are under the null hypothesis of $P I$, hence we will measure the empirical size of the test, whereas in combinations $b$ ) and $c$ ) we are under the alternative hypothesis, so that we will measure the empirical power of the test. We consider 3 alternative possibilities for $u_{s \tau}$ :

$$
\begin{aligned}
\text { i) } u_{s \tau} & =\varepsilon_{s \tau} \quad \varepsilon_{s \tau} \sim \operatorname{Niid}(0,1) \\
\text { ii) } u_{s \tau} & =\varepsilon_{s \tau}-0.5 \varepsilon_{s-1, \tau} \quad \varepsilon_{s \tau} \sim \operatorname{Niid}(0,1) \\
\text { iii) } u_{s \tau} & =0.5 u_{s-1, \tau}+\varepsilon_{s \tau} \quad \varepsilon_{s \tau} \sim \operatorname{Niid}(0,1) .
\end{aligned}
$$

The results are obtained for a sample size of $4 N=200$ and $4 N=400$, based on 5000 replications. We report the results when the order of the fitted models (10)/(11) goes form 1 to 5 . The results for $i$ ), ii) and $i i i)$ are presented in tables $1 . b$, 1.c and 1.d respectively. Clearly the best performance in terms of size and power is obtained with a $P A R(1)$ model for $i)$, with a $P A R(5)$ model for $i i)$ and with a $P A R(2)$ model for $i i i)$. Note that we get a reasonable performance in terms of empirical size and power in small samples for the data generating process (15) without the presence of a structural break as in Perron and Vogelsang (1992). As expected the reported results about the empirical power in tables $1 . b$ to $1 . d$ clearly improved when moving from $N=50$ to $N=100$. We also consider a monte carlo experiment with a change in the mean using the following data generating process:

$$
\begin{aligned}
& x_{s \tau}=-0.975-0.42 D U_{s \tau}+y_{s \tau} \quad s=1,2,3,4 \\
& y_{s \tau}=\varphi_{s} y_{s-1, \tau}+u_{s \tau}
\end{aligned}
$$

With the same combination of values for $\varphi_{s} s=1,2,3$ and 4 that in the case of (15) and also with the three especifications for $u_{s \tau}$ considered in (16). The results are collected in tables 1.e, 1.f and 1.g. Note that, we also obtain the best performance in terms of empirical size and power when the correct order of augmentation is used, that is $P A R(1)$ for $i), P A R(5)$ for $i i)$ 
and $P A R(2)$ for $i i i)$ is used to fit models $(10) /(11)$. Paying attention to the results reported in tables $1 . e$ to $1 . g$ it is possible

to conclude that we observe a reasonable performance in terms of empirical size and power of the test. Finally note that the results reported in tables $1 . \mathrm{b}$ to $1 . \mathrm{d}$ and tables $1 . \mathrm{e}$ to $1 . \mathrm{g}$ are very similar.

\section{External imbalances in the Eurozone: An application to the trade channel adjustment in the eurozone}

The persistent and increasing current account deficits inside the euro area since the mid-1990s have raised concerns about the countries' ability to service their debt. While some member countries have increased their surpluses - mostly Germany but also Finland, Austria and France (North-EU) - other countries - namely, Greece, Ireland, Portugal and Spain (GIPS) widened progressively their deficits up to 2008 when the current economic crisis forced an adjustment. The study of the trade flows and external accounts disequilibria is a recurring topic in international economics. Gourinchas and Rey (2007) have decomposed the external adjustment into a financial (valuation) channel and a trade (net export) channel and show that the deterioration in net exports or net foreign asset positions of a country have to be matched either by future net export growth (trade adjustment channel) or by future increases in the returns of net foreign asset portfolio (financial adjustment channel). The valuation channel is important in the medium-term, whereas the net export channel is more relevant in a long-time horizon. In this context, cointegration techniques are especially suited to capture the long-run adjustment of the trade balance.

A salient feature scarcely studied in this literature is that trade variables are examples of magnitudes with a seasonal pattern. An important part of the instability observed in the estimates of traditional export-import relationships could be due to the omission of the above phenomena. Since the seminal work of Gupta (1964) it is a well documented fact the major importance of seasonality in exports and imports time series, both for volume and prices. According to Mitchell (1927) there are two main sources of seasonal fluctuations in prices and quantities that may cause fluctuations in the demand or supply for many products and consequently in trade flows: climate and custom. The importance of seasonality has been assessed by Alterman et al. (1999) quantifying that for a typical country, seasonal purchases will often amount to one-fifth to one-third of all consumer purchases. Therefore, this behavior will have a direct effect on trade flows originating either from a supply or a demand standpoint. More recently, the IMF (2004) has also emphasized the importance of a proper treatment of the seasonal component in trade series.

There is a increasing bulk of empirical studies analyzing the existence and the nature of long-run or cointegrating relationships between exports and imports. However, the evidence on cointegration is mixed. A summary is presented in table D in the appendix. One of the pioneering works in this area has been the study by Husted (1992) for the US case. Using quarterly trade data for the period 1967-1989, he showed that there is a long-run relationship between imports and exports and that the sign on the estimated cointegrating coefficient is positive. These findings for the US have been in

sharp contrast to those of Fountas and $\mathrm{Wu}(1999)$. The same non-conclusive results can be found in other studies using 
different econometric techniques and covering different samples both in terms of countries and periods considered. ${ }^{4}$ There is also diversity in the type of data used in the papers: some studies use either quarterly or annual data. Moreover, different definitions of the variables have been used in the empirical analysis: some use nominal variables, while others use real variables or the ratios of exports and imports to GDP. However, in none of the papers the authors consider the issue of seasonality, with the exception of Irandoust and Ericsson (2002), that use seasonally adjusted variables in their analysis. An exception is del Barrio Castro et al. (2015) that explicitly deal with seasonal effects using periodic integration and cointegration, and for a group of OECD countries. They obtain long-run relationships for the majority of the countries analyzed.

In this paper the econometric analysis consists of first determining the order of integration of the trade flows and then, if nonstationary, to test and estimate the existence of a long-run relationship between a country's exports and imports implementing state of the art econometrics for periodic integration and cointegration. We use the test of periodic integration proposed in the previous section that allows for a changing mean to the cases of France, Italy, Netherlands, Finland and Spain, where we observed a change in the mean in the variables exports and imports as a proportion of gross domestic product (see figures 1 to 5). It is important to note that in this sample we have limited the analysis to those euro area countries with non-seasonally adjusted data available. Nevertheless, the sample includes both peripheral (debtors) and core countries (creditors) and allow us to analyze the expected break occurred with the launching of the euro.

Our theoretical approach draws on the seminal paper by Husted (1992) who presents a simple theoretical model of a small open economy with no government where there is a representative consumer. The budget constraint must hold for every period. Therefore, the intertemporal budget constraint is given by:

$$
B_{0}=\sum_{t=1}^{\infty} \mu_{t} T B_{t}+\lim _{n \rightarrow \infty} \mu_{n} B_{n}
$$

where $B_{0}$ is international borrowing that can be positive or negative and $T B_{t}$ represents the trade balance in period $t$ (that is, income minus absorption), $X_{t}$ are exports, $M_{t}$ imports, $\lambda_{0}=\frac{1}{\left(1+r_{0}\right)}$ and $\mu_{t}$ is the discount factor (the product of the first $t$ values of $\lambda$. When the last term in equation (18) equals zero, the amount that a country borrows (lends) in international markets equals the present value of the future trade surpluses (deficits).

Assuming that the world interest rate is stationary, Husted(1992) expresses (18) as:

$$
Z_{t}+(1+r) B_{t-1}=X_{t}+B_{t}
$$

\footnotetext{
${ }^{4}$ Some of the other empirical studies that have investigated the existence of long-run co-movement of exports and imports for developed and developing countries include, Arize (2002), Irandoust and Sjoo (2000), Irandoust and Ericsson (2004), Narayan and Narayan (2005), Herzer and Nowak-Lehmann (2006), Hamori (2009), Greenidge et al. (2012) or Nag and Mukherjee (2012). For a large group of countries there is cointegration between exports and imports, as in Hamori (2009) and Nayaran and Nayaran (2005), Holmes et al (2011), although the vector found is not frequently $(1,-1)$.
} 
where $Z_{t}=M_{t}+\left(r_{t}-r\right) B_{t-1}$. Solving forward as Hakkio and Rush (1991) do the next expression is obtained:

$$
M_{t}+r_{t} B_{t-1}=X_{t}+\sum_{j=0}^{\infty} \lambda^{j-1}\left[\Delta X_{t+j}-\Delta Z_{t+j}\right]+\lim _{j \rightarrow \infty} \lambda^{t+j} B_{t+j}
$$

where $\lambda=\frac{1}{(1+r)}$. The left-hand side consists of spending on imports and interest payments (receipts) on net foreign debt (assets). If we substract $X_{t}$ from both sides and multiply by minus one, the left hand side becomes the economy's current account. Assuming that both $Z_{t}$ and $X_{t}$ are $I(1),(20)$ can be rewritten as:

$$
X_{t}=\alpha+M M_{t}-\lim _{j \rightarrow \infty} \lambda^{t+j} B_{t+j}+\epsilon_{t}
$$

where $M M_{t}=M_{t}+r_{t} B_{t-1}$. Assuming that the limit term equals zero, (21) we can obtain a testable equation:

$$
X_{t}=a+b^{*} M M_{t}+e_{t}
$$

where under the null hypothesis that the economy satisfies its intertemporal budget constraint, we expect $b=1$ and $e_{t}$ is stationary. Thus, if both variables are $I(1)$, under the null, they are cointegrated, with a cointegrating vector $(1,-1)$.

We have also assumed earlier than the world interest rate is stationary. Therefore, the term $r_{t} B_{t-1}$ would also be stationary. In practice, we can test for cointegration between exports and imports as, in the long-run, the adjustment works essentially through the trade channel.

As in Azire (2002) we analyze the nominal ratios of both exports to GDP (exp/gdp, hereafter) and imports to GDP (imp/gdp) in levels and also in natural logs. We have collected quarterly data for the five euro-area countries with nonseasonally adjusted data: France, Italy, Netherlands, Finland and Spain. The evolution of the ratios is depicted in figures 1 to 5. The sample ends in 2009Q1 for all the countries considered, but it starts in 1975Q1 for Finland, 1977Q1 for the Netherlands, 1978Q1 for France and finally 1980Q1 for Italy and Spain.

Note that in all these countries we clearly observe a level shift (or change in the mean) that starts in 1999Q1 associated with the creation of the Euro, hence we need to deal with a structural break whewn testing for periodic integration and cointegration between periodically integrated processes $^{5}$. If one does not take into account all the above mentioned and ignores the univariate properties of the series analyzed, it may originate problems of spurious correlations and unstable parameterization.

Ghysels and Osborn (2001, pp.168-171) and del Barrio Castro and Osborn (2008) show an important property related to cointegration in $P I$ processes. In this case, the only cointegration possibilities are periodic cointegration or nonperiodic cointegration, with cointegration for any one season implying cointegration for all seasons, that is, full cointegration. To

\footnotetext{
${ }^{5}$ We follow a similar approach to del Barrio Castro et al. (2015) but allowing for a changing mean in the evolution of the exp/gdp and imp/gdp time series.
} 
have full nonperiodic cointegration (equivalent in this case to conventional cointegration) the involved processes must share the same $\varphi_{s}$ coefficients in (2). Indeed, the conventional class of integrated, or $I(1)$, time series form a special case of $P I$ processes where the cointegrating vectors between adjacent (seasonal) observations have the form $(1,-1)$.

Hence, when we analyze the external balance, if exp/gdp and imp/gdp or their natural logs are cointegrated with a $(1,-1)$ vector both processes must share the same $\varphi_{s}$ coefficients in $(10,11)$. Finally in order to check the possibility of a long run relationship between exp/gdp and imp/gdp we are going to use the Likelihood Ratio residual based test $L R_{C R}$ proposed by del Barrio Castro and Osborn (2008) to test the null of no cointegration between PI processes. Note that in this case we are assuming that there is a co-break ${ }^{6}$.

According to Irandoust and Sjöö (2000) the theory suggests that cointegration is to be expected under the maintained hypothesis that the economy is working properly, and that breaking international budget constraints leads to a lack of cointegration. Therefore, if the time series paths of imports and exports diverge, and not cointegrate, countries would exhibit permanent and increasing external disequilibria. These imbalances may be explained both by the existence of a series of technological shocks (or, simply a continuos productivity gap) or, alternatively, by a permanent financing of a bubble in a particular market. If the external imbalance continues to be large when global investors no longer wish to add more assets to their portfolio, the trade deficit will not be sustainable, and an economic adjustment must occur via interest rates and/or exchange rates. However, the launching of the euro has given raise to a regime change in the adjustment mechanism among the EMU member countries.

In this subsection we discuss the empirical results for France, Italy, Netherlands, Finland and Spain. As mentioned earlier and by looking at figures 1 to 5 , we observe that these countries present a clear change in the mean, possibly associated with the creation of the Euro. Hence in this section we use the $L R_{i o}(\lambda)$ test, assuming that the break date is known. We should also note that not all the countries show the same direction in the mean-change: whereas in France, the Netherlands and Finland the variables' level increases after the break (for both imports and exports), in Italy and Spain it decreases.

First of all, we determine the order on the unrestricted and restricted $P A R(p)$ models $(10) /(11)$ using the $A I C$ and $B I C$ criteria and setting a maximum order of $p=5$. Next, we report as well the results obtained for the $F_{p e r}$ statistic to test the null hypothesis of non periodic variation in the coefficients in the model (10) where the null hypothesis $H_{0}: \phi_{j s}=\phi_{j}$ for $j=1, \cdots p$. We also present the results obtained for the $L R_{i o}(\lambda)$ test described in the previous subsection, together with those obtained with the $L R_{C R}$ to test the null of no cointegration between the ratios exp/gdp and imp/gdp assuming that there is a co-break. These results can be found in table 2 .

We find evidence against the null of non periodicity in the coefficients in the model $(10) H_{0}: \phi_{j s}=\phi_{j}$ for $j=1, \cdots p$. using the $F_{p e r}$ test for Italy, Finland and the Netherlands (in levels). However, this is not the case of France and Spain. Using the proposed $L R_{i o}(\lambda)$ test we reject the null hypothesis of periodic integration at a $5 \%$ for France, that is we find

\footnotetext{
${ }^{6}$ We leave for future research the extension of the Gregory and Hansen (1996) approach to the case of periodic cointegration.
} 
evidence that for France exp/gdp and imp/gdp are stationary in levels and logs. In levels we reject the null of periodic integration at $5 \%$ of significance in the case of Finland for imp/gdp and the Netherlands for exp/gdp. For Spain we reject the null of $P I$ at a $10 \%$ level for imp/gdp and $\ln (\mathrm{imp} / \mathrm{gdp})$. Finally in the case of the Netherlands the null is rejected at a $10 \%$ level for $\ln (\exp / \mathrm{gdp})$ and $\ln (\mathrm{imp} / \mathrm{gdp}$. Hence overall our conclusion is that we find evidence pointing towards periodic integration at a $5 \%$ at least in logs, excepting in the case of France.

Concerning cointegration, we present the results of the $L R_{C R}$ test in the last column of the table. We find evidence of cointegration between exp/gdp and imp/gdp in logs for the cases of the Netherlands and Finland, and also reject the null of no cointegration at $10 \%$ level of significance for Spain.

As mentioned before, Ghysels and Osborn (2001) and del Barrio Castro and Osborn (2008) show that cointegration between $P I$ processes should be either full periodic cointegration or full nonperiodic cointegration. To have full nonperiodic cointegration (equivalent in this case to conventional cointegration) the involved processes must share the same $\varphi_{s}$ coefficients in $(10,11)$. In the case of Finland in some cases the coefficients of $\ln (\exp / g d p)$ and $\ln (\mathrm{imp}(\mathrm{gdp})$ are quite different, hence it seems that we face full periodic cointegration. In the case of the Netherlands we did not observe the same kind of divergence in the value of the coefficients and, finally, in the case of Spain the coefficients are quite similar in levels and we observe more divergence between the coefficients in logs. Overall we find evidence of cointegration in the case for Finland, the Netherlands and Spain, but not in the case of Italy. Finally, the variables exp/gdp and imp/gdp in levels and logs are stationary in France.

\section{Concluding remarks.}

In this paper the Likelihood Ratio of Boswijk and Franses (1996) to test the null of periodic integration has been extended allowing for a changing mean in the spirit of the approach developed by Perron(1990) and Perron and Vogelsang (1992a) in standard unit roots tests. We report the asymptotic distribution of the test and show that is the square of the distribution obtained by Perron and Vogelsang (1992a,1992b). A Monte Carlo investigation shows that the proposed test has good behavior in terms of size and power. Finally, in an empirical section we illustrate the use of the test. We present evidence of power advantages in an empirical application to the trade balance sustainability for the euro area countries. The creation of the euro had a significant effect on the deterministic component of the variables in all the countries in our sample. Once we account for periodic integration and a mean change, we find cointegration in Finland, the Netherlands and Spain (at 10\% level of significance). The fact that cointegration between exports and imports can be rejected in the case of Italy signals the important difficulties of this economy to implement structural reforms and gain real competitiveness in the long-run. 


\section{References}

[1] Alterman, W.F., Diewert, W. E. and R. C.Feenstra. (1999) International Trade Price Indexes and Seasonal Commodities (Washington: Bureau of Labor Statistics).

[2] Arize, A.C. (2002) Imports and exports in 50 countries. Tests of cointegration and structural breaks, International Review of Economics and Finance, vol. 11, pp. 101-115.

[3] Berenguer-Rico V. and J. Ll. Carrion-i-Silvestre (2011) Regime shifts in stock-flow I(2)-I(1) systems: the case of US fiscal sustainability, Journal of Applied Econometrics, 26, 298-321.

[4] Boswijk H.P. and P.H. Franses (1995) Testing for periodic integration,Economics Letters, 48, 241-248.

[5] Boswijk H.P. and P.H. Franses (1996) Unit roots in periodic autoregressions, Journal of Time Series Analysis 17, $221-245$.

[6] Choi I. (2015) Almost All About Unit Roots, Cambridge University Press, Cambridge.

[7] del Barrio Castro, T., M. Camarero and C. Tamarit (2015) An analysis of the trade balance for OECD countries using periodic integration and cointegration, Empirical Economics, 49, 389-402.

[8] del Barrio Castro T. and D.R. Osborn (2008) Cointegration For Periodically Integrated Processes, Econometric Theory, 24, 109-142.

[9] del Barrio Castro T. and D. R. Osborn (2011) Nonparametric Tests for Periodic Integration, Journal of Time Series Econometrics, 3, 1-35.

[10] Franses, P. H. (1994) A multivariate approach to modeling univariate seasonal time series, Journal of Econometrics, 63, 133-151.

[11] Franses, P.H. and R. Paap (2004) Periodic Time Series Models. Oxford University Press.

[12] Franses P.H. and T.J. Vogelsang (1998) On Seasonal Cycles, Unit Roots, And Mean Shifts, The Review of Economics and Statistics, 80, 231-240.

[13] Fountas, S. and J.-L. Wu (1999): "Are The U.S. Current Account Deficits Really Sustainable?," International Economic Journal, Korean International Economic Association, vol. 13(3), pages 51-58.

[14] Gersovitz M. and J.G. McKinnon (1978) Seasonality in regression: An application of smoothness priors, Journal of the American Statistical Association, 73, 264-273.

[15] Ghysels, E. (1990). Unit-Root Tests and the Statistical Pitfalls of Seasonal Adjustment: The Case of U.S. Postwar Real Gross National Product, Journal of Business and Economic Statistics, 8, 145-152. 
[16] Ghysels E. and P. Perron (1993), The Effect of Seasonal Adjustment Filters on Tests for Unit Roots, Journal of Econometrics, 55, 57-99.

[17] Ghysels E. and D.R. Osborn (2001) The Econometric Analysis of Seasonal Time Series. Cambridge University Press.

[18] Gourinchas, P. O. and H. Rey (2007) International Financial Adjustment", Journal of Political Economy, $115,4$.

[19] Gregory and B. Hansen (1996) Residual-based tests for cointegration in models with regime shifts, Journal of Econometrics, 70, 99-125.

[20] Greenidge, K., Drakes, L., Thomas, C. and R. Craigwell (2012) Threshold Effects of Sovereign Debt: Evidence From the Caribbean, IMF Working Papers 12/157, International Monetary Fund.

[21] Gupta, J.B. (1965) Seasonality in World Financial and Trade Data, IMF Staff Papers, 12, 353-364.

[22] Hakkio, C. S. and Rush, M. (1991): "Is the Budget Deficit "Too Large?"," Economic Inquiry, 29, 429-45.

[23] Hamori, S. (2009): "The sustainability of trade accounts of the G-7 countries", Applied Economics Letters, 16, 16911694.

[24] Hansen L.P. and T.J. Sargent (1993) Seasonality and approximation errors in rational expectation models, Journal of Econometrics, 55, 21-56.

[25] Harvey, D.I., Leyboourne, S.J. and P. Newbold (2002) Seasonal unit root tests with seasonal mean shifts, Economics Letters, 76, 295-302.

[26] Hassler, U. and P. M. M. Rodrigues (2004) Seasonal Unit Root Tests Under Structural Breaks, Journal of Time Series Analysis, 25, 33-53.

[27] Herzer, D. and F. Nowak-Lehmann (2006): "Is there a long-run relationship between exports and imports in Chile?", Applied Economics Letters, vol. 13, pp. 981-986.

[28] Holmes, M., Panagiotidis, T. and A. Sharma (2011) The sustainability of India's current account, Applied Economics, 43, 219-229.

[29] Husted, S. (1992): "The Emerging U.S. Current Account Deficit in the 1980s: A Cointegration Analysis", The Review of Economics and Statistics, vol. 74(1), pp. 159-166. The MIT Press.

[30] Hylleberg, S. (1995). Tests for Seasonal Unit Roots: General to Specific or Specific to General? Journal of Econometrics, $69,5-25$.

[31] Hylleberg, S., R. Engle, C. W. J. Granger and B. S. Yoo (1990). "Seasonal Integration and Co-Integration." Journal of Econometrics, 44(1-2): 215-238. 
[32] IMF (2004) Treatment of Seasonal Products, in Producer Price Index Manual, ch. 22. IMF. Washington.

[33] Irandoust, M. and B. Sjoo (2000) The Behavior of the Current Account in Response to Unobservable and Observable Shocks, International Economic Journal, 14, 41-57.

[34] Irandoust, M. and J. Ericsson (2004) Are imports and exports cointegrated? An international comparison, Metroeconomica, 55, 49-64.

[35] Johansen, S. (1995) Likelihood-Based Inference in Cointegrated Vector Autoregressive Models, Oxford University Press, Oxford.

[36] Maekawa, K. (1997) Periodically integrated autoregression with a structural break, Mathematics and Computers in simulations, 43, 467-472.

[37] Maravall, A. (1993), Stochastic Linear Trends, Journal of Econometrics, 56, 5-37.

[38] Mitchell, W.C., (1927) Business Cycles (New York: National Bureau of Economic Research).

[39] Narayan, P.K. and S. Narayan (2005) Are exports and imports cointegrated? Evidence from 22 least developed countries, Applied Economics Letters, 12, 375-378.

[40] Nag, B. and J. Mukherjee (2012) The sustainability of trade deficits in the presence of endogenous structural breaks: Evidence from the Indian economy, Journal of Asian Economics, 23, 519-526.

[41] Nunes L.C. and P. M. M. Rodrigues (2011) On LM-type tests for seasonal unit roots in the presence of a break in trend, Journal of Time Series Analysis, 32, 08-134.

[42] Olekalns, N. (1994) Testing for Unit Roots in Seasonally Adjusted Data, Economic Letters, 45, $273-279$.

[43] Osborn, D. (1991) The implications of periodically varying coefficients for seasonal time-series processes, Journal of Econometrics, 48, 373-384.

[44] Osborn, D.R. (1988) Seasonality and habit persistence in a life-cycle model of consumption, Journal of Applied Econometrics, 3, 255-266.

[45] Perron, P. (1990) Testing for a Unit Root in time Series with Changing Mean, Journal of Business and Economic Statistics, 8, 153-162.

[46] Perron, P. and T.J. Vogelsang (1992a) Testing for a Unit Root in time Series with Changing Mean: Corrections and Extensions, Journal of Business and Economic Statistics, 10, 467-470.

[47] Perron, P. and T.J. Vogelsang (1992b) Nonstationarity and Level Shifts with an Application to purchase Power Parity, Journal of Business and Economic Statistics, 10, 301-320. 
[48] Rodrigues, P.M.M. and A.M.R. Taylor (2007) Efficient tests of the seasonal unit root hypothesis, Journal of Econometrics, 141, 548-573.

[49] Zivot E. and D. W. K. Andrews (1992) Further Evidence on the Great Crash, the Oil-Price Shock, and the Unit-Root Hypothesis, Journal of Business 63 Economic Statistics, 10, 251-270.

\section{A Proof}

Proof. First note that from (5) it is possible to write:

$$
\mathbf{y}_{\tau}-\mathbf{y}_{\tau-1}=\left(\boldsymbol{\Theta}_{0}+\boldsymbol{\Theta}_{1} L\right) \mathbf{\Psi}(L)^{-1} \mathbf{e}_{\tau}=\mathbf{C}(L) \mathbf{u}_{\tau}
$$

with $\mathbf{u}_{\tau}=\boldsymbol{\Psi}(L)^{-1} \mathbf{e}_{\tau}$, them we have that:

$$
\begin{aligned}
\mathbf{y}_{\tau} & =\mathbf{y}_{0}+\mathbf{C}(1) \sum_{j=1}^{\tau} \mathbf{u}_{j}+O_{p}(1) \\
& =\mathbf{y}_{0}+\mathbf{a b}^{\prime} \sum_{j=1}^{\tau} \mathbf{u}_{j}+O_{p}(1)
\end{aligned}
$$

Replace $\mathbf{u}_{\tau}$ by $\left(\gamma D(N B)_{\tau}+\mathbf{u}_{\tau}\right)$, hence we have:

$$
\mathbf{y}_{\tau}=\mathbf{y}_{0}+\mathbf{a} \mathbf{b}^{\prime} \sum_{j=1}^{\tau} \mathbf{u}_{j}+\mathbf{a} \mathbf{b}^{\prime} \gamma D U_{\tau}+O_{p}(1)
$$

As in Perron and Vogelsang (1992a) it is possible to write for $\tilde{y}_{s \tau}=y_{s \tau}-\hat{\mu}_{s}-\hat{\gamma}_{s}^{*} D U_{s \tau}$, where $\bar{y}_{s}^{a}=N_{b}^{-1} \sum_{\tau=1}^{N_{b}} y_{s \tau}=$ $\lambda^{-1} N^{-1} \sum_{\tau=1}^{N_{b}} y_{s \tau}$ and $\bar{y}_{s}^{b}=\left(N-N_{b}\right)^{-1} \sum_{\tau=N_{b}+1}^{N} y_{s \tau}=(1-\lambda)^{-1} N^{-1} \sum_{\tau=N_{b}+1}^{N} y_{s \tau}$ :

$$
\begin{aligned}
& \tilde{y}_{s \tau}=y_{s \tau}-\bar{y}_{s}^{a}=\mathbf{a}_{s} S_{\tau}-\mathbf{a}_{s} \bar{S}_{a} \quad \text { if } \quad \tau \leq N_{B} \\
& \tilde{y}_{s \tau}=y_{s \tau}-\bar{y}_{s}^{b}=\mathbf{a}_{s} S_{\tau}-\mathbf{a}_{s} \bar{S}_{b}-\mathbf{a}_{s} \mathbf{b}^{\prime} \gamma\left(1-\lambda^{\prime}\right) /(1-\lambda) \quad \text { if } \quad N_{B} \leq \tau \leq N_{B}^{\prime} \\
& \tilde{y}_{s \tau}=y_{s \tau}-\bar{y}_{s}^{b}=\mathbf{a}_{s} S_{\tau}-\mathbf{a}_{s} \bar{S}_{b}+\mathbf{a}_{s} \mathbf{b}^{\prime} \gamma-\mathbf{a}_{s} \mathbf{b}^{\prime} \gamma\left(1-\lambda^{\prime}\right) /(1-\lambda) \quad \text { if } \quad N_{B}^{\prime} \leq \tau \leq N
\end{aligned}
$$

with $S_{\tau}=\mathbf{b}^{\prime} \sum_{j=1}^{\tau} \mathbf{u}_{j}, \bar{S}_{a}=N_{b}^{-1} \sum_{\tau=1}^{N_{b}} S_{\tau}=\lambda^{-1} N^{-1} \sum_{\tau=1}^{N_{b}} S_{\tau}$ and $\bar{S}_{b}=\left(N-N_{b}\right)^{-1} \sum_{\tau=N_{b}+1}^{N} S_{\tau}=(1-\lambda)^{-1} N^{-1} \sum_{\tau=N_{b}+1}^{N} S_{\tau}$. Additionally we define $\tilde{y}_{s \tau}^{*}$, without serial correlation, as the residuals from a projection of $\tilde{y}_{s \tau}$ on $D(N B)_{s, \tau}$ and ,in the presence of serial correlation, as the the residuals from a projection of $\tilde{y}_{s \tau}$ on $D(N B)_{s, \tau}$ and its $p-1$ lags. Assume for simplicity the absence of serial correlation, hence:

$$
\begin{aligned}
& \tilde{y}_{s \tau}^{*}=\mathbf{a}_{s} S_{\tau}-\mathbf{a}_{s} \bar{S}_{a} \text { if } \tau \leq N_{B} \\
& \tilde{y}_{s \tau}^{*}=0 \text { if } \tau=N_{B}+1 \\
& \tilde{y}_{s \tau}^{*}=\mathbf{a}_{s} S_{\tau}-\mathbf{a}_{s} \bar{S}_{b}-\mathbf{a}_{s} \mathbf{b}^{\prime} \gamma\left(1-\lambda^{\prime}\right) /(1-\lambda) \quad \text { if } \quad N_{B}+1 \leq \tau \leq N_{B}^{\prime} \\
& \tilde{y}_{s \tau}^{*}=\mathbf{a}_{s} S_{\tau}-\mathbf{a}_{s} \bar{S}_{b}+\mathbf{a}_{s} \mathbf{b}^{\prime} \gamma-\mathbf{a}_{s} \mathbf{b}^{\prime} \gamma\left(1-\lambda^{\prime}\right) /(1-\lambda) \quad \text { if } \quad N_{B}^{\prime} \leq \tau \leq N
\end{aligned}
$$

Following the lines of the proof of Theorem 1 in Boswijk and Franses (1996) it is convenient to write (10)/(11) using conventional time subscripts and seasonal dummy variable notation $\left(D_{s t}\right.$ taking the value unity when observation $t$ falls in 
season $s$ and zero otherwise). Employing this notation yields the representation (see Boswijk and Franses, 1996, p. 238):

$$
\tilde{y}_{t}^{*}=\pi_{1} D_{1 t} \tilde{y}_{t-1}^{*}+\sum_{s=1}^{4} \varphi_{s} D_{s t} \tilde{y}_{t-1}^{*}+\sum_{s=1}^{4} \sum_{j=1}^{p-1} \psi_{j s}\left(D_{s t} \tilde{y}_{t-j}^{*}-\varphi_{s-j} D_{s t} \tilde{y}_{t-j-1}^{*}\right)+\varepsilon_{t}
$$

where the restrictions $\varphi_{1} \varphi_{2} \varphi_{3} \varphi_{4}=1$ is imposed. Note that since the deterministic terms enter unrestrictedly then $\tilde{y}_{t}^{*}$ are the residuals as defined in $(24) /(25)$. Let $\theta=\left[\theta_{1}, \theta_{2}^{\prime}, \theta_{3}^{\prime}\right]^{\prime}$ denote the full parameter vector with $\theta_{1}=\pi_{1}, \theta_{2}^{\prime}=\left[\varphi_{2}, \varphi_{3}, \varphi_{4}\right]$ and $\theta_{3}^{\prime}=\left[\psi_{11}, \cdots, \psi_{1, p-1}, \cdots, \psi_{41}, \cdots, \psi_{4, p-1}\right]$. Under the null hypothesis $\pi_{1}=0$, hence this parameter is associated with the unit root while, $\varphi_{2}, \varphi_{3}$ and $\varphi_{4}$ are cointegration parameters (with $\varphi_{1}$ defined from the periodic unit root restriction as $\left.\varphi_{1}=\left(\varphi_{2} \varphi_{3} \varphi_{4}\right)^{-1}\right)$, and $\theta_{3}$ collects the parameters associated with the stationary regressors in (26). Let $z_{t}=\left[z_{t}^{1}, z_{t}^{2 \prime}, z_{t}^{3 \prime}\right]^{\prime}$ be defined conformably with $\theta$ as $z_{t}=\partial \tilde{y}_{t} / \partial \theta$, and hence

$$
z_{t}^{1}=D_{1 t} \tilde{y}_{t-1}, \quad z_{t}^{2}=H^{\prime} u_{t} \quad u_{t}=\left[u_{1 t}, u_{2 t}, u_{3 t}, u_{4 t}\right]^{\prime}
$$

where :

$$
\begin{aligned}
u_{s t} & =D_{s t} \tilde{y}_{t-1}-\sum_{i=1}^{p-1} \psi_{i, s+i} D_{s+i, t} \tilde{y}_{t-i-1} \quad s=1,2,3,4 \\
H^{\prime} & =\left[\begin{array}{llll}
-\frac{\varphi_{1}}{\varphi_{2}} & 1 & 0 & 0 \\
-\frac{\varphi_{1}}{\varphi_{3}} & 0 & 1 & 0 \\
-\frac{\varphi_{1}}{\varphi_{4}} & 0 & 0 & 1
\end{array}\right] .
\end{aligned}
$$

Note that for $z_{t}^{1}$ we have that

$$
\begin{aligned}
\sigma^{-2} N^{-1} \sum_{t=1}^{T} z_{t}^{1} \varepsilon_{t}= & \sigma^{-2} N^{-1} \sum_{t=1}^{T} D_{1 t} \tilde{y}_{t-1} \varepsilon_{t}=\sigma^{-2} N^{-1} \sum_{\tau=1}^{N} \tilde{y}_{4, \tau-1} \varepsilon_{1 \tau}= \\
= & \sigma^{-2} N^{-1} \sum \mathbf{a}_{4} S_{\tau-1} \varepsilon_{1 \tau}-\sigma^{-2} N^{-1} \mathbf{a}_{4} \bar{S}_{a} \sum_{\tau=1}^{N_{b}} \varepsilon_{1 \tau}- \\
& -\sigma^{-2} N^{-1} \mathbf{a}_{4} \bar{S}_{a} \sum_{\tau=N_{b}+1}^{N} \varepsilon_{1 \tau}+O_{p}(1)
\end{aligned}
$$

and

$$
\begin{aligned}
\sigma^{-2} N^{-2} \sum_{t=1}^{T}\left(z_{t}^{1}\right)^{2}= & \sigma^{-2} N^{-2} \sum_{t=1}^{T}\left(D_{1 t} \tilde{y}_{t-1}\right)^{2}=\sigma^{-2} N^{-2} \sum_{\tau=1}^{N}\left(\tilde{y}_{4, \tau-1}\right)^{2}= \\
= & \sigma^{-2} N^{-2} \sum\left(\mathbf{a}_{4} S_{\tau-1}\right)^{2}+\sigma^{-2} N^{-1} \lambda\left(\mathbf{a}_{4} \bar{S}_{a}\right)^{2}+\sigma^{-2} N^{-1}(1-\lambda)\left(\mathbf{a}_{4} \bar{S}_{b}\right)^{2}+ \\
& -2 \sigma^{-2} N^{-2} \mathbf{a}_{4} \bar{S}_{a} \sum_{\tau=1}^{N_{b}}\left(\mathbf{a}_{4} S_{\tau-1}\right)-2 \sigma^{-2} N^{-2} \mathbf{a}_{4} \bar{S}_{b} \sum_{\tau=N_{b}+1}^{N}\left(\mathbf{a}_{4} S_{\tau-1}\right)+o_{p}(1) .
\end{aligned}
$$


From lemma 1 in Boswijk and Franses (1996) it is possible to establish:

$$
\begin{aligned}
\sigma^{-2} N^{-1} \sum \mathbf{a}_{s} S_{\tau-1} \varepsilon_{1 \tau} & \Rightarrow \sigma^{-2} \omega a_{s} \int_{0}^{1} w(r) d E_{1}(r) \\
\sigma^{-1} N^{-3 / 2} \sum \mathbf{a}_{s} S_{\tau-1} & \Rightarrow \sigma^{-1} \omega a_{s} \int_{0}^{1} w(r) d r \\
\sigma^{-1} N^{-1 / 2} \sum \varepsilon_{1 \tau} & \Rightarrow \sigma^{-1} E_{1}(1) \\
\sigma^{-1} N^{-3 / 2} \sum_{N_{B}} \mathbf{a}_{s} S_{\tau-1} & \Rightarrow \sigma^{-1} \omega a_{4} \int_{\lambda}^{1} w(r) d r \\
\sigma^{-1} N^{-1 / 2} \sum_{N_{B}} \varepsilon_{1 \tau} & \Rightarrow \sigma^{-1}\left(E_{1}(1)-E_{1}(\lambda)\right) \\
\sigma^{-2} N^{-2} \sum\left(\mathbf{a}_{s} S_{\tau-1}\right)^{2} & \Rightarrow \sigma^{-2} \omega^{2} a_{s}^{2} \int_{0}^{1}[w(r)]^{2} d r \\
\sigma^{-1} N^{-1 / 2} \mathbf{a}_{s} \bar{S}_{a} & =\sigma^{-1} \lambda^{-1} N^{-3 / 2} \sum_{\tau=1}^{N_{b}} \mathbf{a}_{s} S_{\tau} \Rightarrow \sigma^{-1} \omega a_{s} \lambda^{-1} \int_{0}^{\lambda} w(r) d r \\
\sigma^{-1} N^{-1 / 2} \mathbf{a}_{s} \bar{S}_{b} & =\sigma^{-1}(1-\lambda)^{-1} N^{-3 / 2} \sum_{\tau=N_{b}+1}^{N} \mathbf{a}_{s} S_{\tau} \Rightarrow \sigma^{-1} \omega a_{s}(1-\lambda)^{-1} \int_{\lambda}^{1} w(r) d r
\end{aligned}
$$

Hence we have that:

$$
\begin{aligned}
\sigma^{-2} N^{-1} \sum_{t=1}^{T} z_{t}^{1} \varepsilon_{t} \Rightarrow & \sigma^{-2} \omega a_{4}\left[\int_{0}^{1} w(r) d E_{1}(r)-\lambda^{-1}\left[\int_{0}^{\lambda} w(r) d r\right] E_{1}(\lambda)+\right. \\
& \left.-(1-\lambda)^{-1}\left[\int_{\lambda}^{1} w(r) d r\right]\left(E_{1}(1)-E_{1}(\lambda)\right)\right]= \\
= & \sigma^{-2} \omega a_{4}\left[N U\left(E_{1}\right),(\lambda)\right]
\end{aligned}
$$

where :

$$
\begin{aligned}
{\left[N U\left(E_{1}\right),(\lambda)\right]=} & \int_{0}^{1} w(r) d E_{1}(r)-\lambda^{-1}\left[\int_{0}^{\lambda} w(r) d r\right] E_{1}(\lambda)- \\
& -(1-\lambda)^{-1}\left[\int_{\lambda}^{1} w(r) d r\right]\left(E_{1}(1)-E_{1}(\lambda)\right)
\end{aligned}
$$

and:

$$
\begin{aligned}
\sigma^{-2} N^{-2} \sum_{t=1}^{T}\left(z_{t}^{1}\right)^{2} \Rightarrow & \sigma^{-2} \omega^{2} a_{4}^{2} \int_{0}^{1}[w(r)]^{2} d r--\sigma^{-2} \omega^{2} a_{4}^{2} \lambda^{-1}\left(\int_{0}^{\lambda} w(r) d r\right)^{2} \\
& -\sigma^{-2} \omega^{2} a_{4}^{2}(1-\lambda)^{-1}\left(\int_{\lambda}^{1} w(r) d r\right)^{2} \\
= & \sigma^{-2} \omega^{2} a_{4}^{2}[D E]
\end{aligned}
$$

where :

$$
\begin{aligned}
{[D E(\lambda)]=} & \int_{0}^{1}[w(r)]^{2} d r-\lambda^{-1}\left(\int_{0}^{\lambda} w(r) d r\right)^{2} \\
& -(1-\lambda)^{-1}\left(\int_{\lambda}^{1} w(r) d r\right)^{2}
\end{aligned}
$$


Note also that form (27) and following the lines of (28)-(32) it is possible to establish:

$$
\begin{aligned}
\sigma^{-2} N^{-1} \sum z_{t}^{2} \varepsilon_{\tau} \Rightarrow & \sigma^{-2} \omega H^{\prime} A \Psi(1)^{\prime}[N U(E),(\lambda)] \\
\sigma^{-2} N^{-2} \sum z_{t}^{2} z_{t}^{1} \Rightarrow & \sigma^{-2} \omega^{2} H^{\prime} A \Psi(1)^{\prime} A_{1}[D E(\lambda)] \\
\sigma^{-2} N^{-2} \sum z_{t}^{2} z_{t}^{2 \prime} \Rightarrow & \sigma^{-2} \omega^{2} H^{\prime} A \Psi(1)^{\prime} \Psi(1) A H[D E(\lambda)] \\
\text { where } & : \\
{[N U(E),(\lambda)]=} & \int_{0}^{1} w(r) d E(r)- \\
& -\lambda^{-1}\left[\int_{0}^{\lambda} w(r) d r\right] E(\lambda)+ \\
& -(1-\lambda)^{-1}\left[\int_{\lambda}^{1} w(r) d r\right](E(1)-E(\lambda)) \\
A= & \operatorname{diag}\left[a_{4}, a_{1}, a_{2}, a_{3}\right]=\operatorname{diag}\left[\varphi_{2} \varphi_{3} \varphi_{4}, 1, \varphi_{2}, \varphi_{2} \varphi_{3}\right] \\
A_{1}= & \operatorname{diag}\left[a_{4}, 0,0,0\right]=\operatorname{diag}\left[\varphi_{2} \varphi_{3} \varphi_{4}, 0,0,0\right] .
\end{aligned}
$$

and $[D E(\lambda)]$ defined in (32). Under the periodic unit root null hypothesis the $P A R(p-1)$ regressors $D_{s t} y_{t-j}-\varphi_{s-j} D_{s t} y_{t-j-1}$ collected in the vector $z_{t}^{3}$ are stationary with

$$
\begin{aligned}
\sigma^{-2} N^{-1} \sum z_{t}^{3} \varepsilon_{\tau} & \Rightarrow N\left(0, V_{3}\right) \\
\sigma^{-2} N^{-2} \sum z_{t}^{3} z_{t}^{3 \prime} & \rightarrow V_{3} .
\end{aligned}
$$

As a consequence of the different rates of convergence for the parameter estimates corresponding to the nonstationary $P I$ regressors and those for the stationary $P A R(p-1)$ component in the augmented regression (10) or (11), we have that:

$$
\begin{aligned}
& N^{-2} \sum z_{t}^{3} z_{t}^{2 \prime}=O_{p}(1) \\
& N^{-2} \sum z_{t}^{3} z_{t}^{1}=O_{p}(1) .
\end{aligned}
$$

Following Boswijk and Franses (1996), we establish the distribution of $L R_{i o}(\lambda)$ using

$$
L R_{i o}(\lambda)=\frac{\left(N \hat{\theta}_{1}\right)^{2}}{\left(Y_{N}^{-1} Q_{\theta} Y_{N}^{-1}\right)^{11}}+o_{p}(1) .
$$

where $Y_{N}=\operatorname{diag}\left[N \times I_{4}, N^{1 / 2} \times I_{4(p-1)}\right],\left(Y_{N}^{-1} Q_{\theta} Y_{N}^{-1}\right)^{11}$ is the first element of the principal diagonal of the inverse matrix $\left(Y_{N}^{-1} Q_{\theta} Y_{N}^{-1}\right)^{-1}, N \hat{\theta}_{1}$ is the first element of $\left(Y_{N}^{-1} Q_{\theta} Y_{N}^{-1}\right)^{-1} Y_{N}^{-1} q_{\theta}$, and $q_{\theta}$ and $Q_{\theta}$ are the score and negative of the Hessian matrix, respectively, formulated in terms of $\theta$. Note that, as in Boswijk and Franses (1996),

$$
\left(Y_{N}^{-1} Q_{\theta} Y_{N}^{-1}\right)^{-1} Y_{N}^{-1} q_{\theta}=\left(\sigma^{-2} Y_{N}^{-1} \sum z_{t} z_{t}^{\prime} Y_{N}^{-1}\right)^{-1} \sigma^{-2} Y_{N}^{-1} \sum z_{t} \varepsilon_{t} .
$$


From (31), (32), (33) and (34) it is easy to see that

$$
\begin{aligned}
Y_{N}^{-1} Q_{\theta} Y_{N}^{-1} & \Rightarrow\left[\begin{array}{cc}
K^{\prime} K[D E(\lambda)] & 0 \\
0 & V_{3}
\end{array}\right] \\
Y_{N}^{-1} q_{\theta} & \Rightarrow\left[\begin{array}{c}
\sigma^{-1} K^{\prime}[N U(E),(\lambda)] \\
N\left(0, V_{3}\right)
\end{array}\right] \\
\text { where } & : \\
K & =\frac{\omega}{\sigma}\left[A_{1}: \Psi(1) A H\right] .
\end{aligned}
$$

Therefore,

$$
\left(Y_{N}^{-1} Q_{\theta} Y_{N}^{-1}\right)^{-1} Y_{N}^{-1} q_{\theta} \Rightarrow\left[\begin{array}{c}
{[D E(\lambda)]^{-1} \sigma^{-1}\left(K^{\prime} K\right)^{-1} K^{\prime}[N U(E),(\lambda)]} \\
N\left(0, V_{3}^{-1}\right)
\end{array}\right] .
$$

Note that $[D E(\lambda)]$ is a scalar and also that for $\sigma^{-1}\left(K^{\prime} K\right)^{-1} K^{\prime}[N U(E),(\lambda)]$ it is possible to write:

$$
\begin{aligned}
\sigma^{-1}\left(K^{\prime} K\right)^{-1} K^{\prime}[N U(E)]= & \int_{0}^{1} w(r) d S(r)- \\
& -\lambda^{-1}\left[\int_{0}^{\lambda} w(r) d r\right] S(\lambda) \\
& +(1-\lambda)^{-1}\left[\int_{\lambda}^{1} w(r) d r\right](S(1)-S(\lambda))
\end{aligned}
$$

where :

$$
S(r)=\sigma^{-1}\left(K^{\prime} K\right)^{-1} K^{\prime} E(r) .
$$

Now, partitioning $K=\left[K_{1} \vdots K_{2}\right]$ to focus on the first element of $\left(Y_{N}^{-1} Q_{\theta} Y_{N}^{-1}\right)^{-1} Y_{N}^{-1} q_{\theta}$, namely $N \hat{\theta}_{1},(37)$ and (38) implies

$$
\begin{aligned}
N \hat{\theta}_{1} \Rightarrow & {[D E(\lambda)]^{-1}\left\{\int_{0}^{1} w(r) d S_{1}(r)-\right.} \\
& -\lambda^{-1}\left[\int_{0}^{\lambda} w(r) d r\right] S_{1}(\lambda)- \\
& \left.-(1-\lambda)^{-1}\left[\int_{\lambda}^{1} w(r) d r\right]\left(S_{1}(1)-S_{1}(\lambda)\right)\right\}
\end{aligned}
$$

where :

$$
\begin{aligned}
S_{1}(r) & =\sigma^{-1}\left(K_{1}^{\prime} M_{2} K_{1}\right)^{-1} K_{1}^{\prime} M_{2} E(r) \\
M_{2} & =I-K_{2}\left(K_{2}^{\prime} K_{2}\right)^{-1} K_{2}^{\prime} .
\end{aligned}
$$


In Boswijk and Franses (1996) it is shown that $S_{1}(r)=\left(K_{1}^{\prime} M_{2} K_{1}\right)^{-1 / 2} w(r)$ hence we have:

$$
\begin{aligned}
N \hat{\theta}_{1} \Rightarrow & \left(K_{1}^{\prime} M_{2} K_{1}\right)^{-1 / 2}[D E]^{-1}\left\{\int_{0}^{1} w(r) d w(r)-\right. \\
& -\lambda^{-1}\left[\int_{0}^{\lambda} w(r) d r\right] w(\lambda)- \\
& \left.-(1-\lambda)^{-1}\left[\int_{\lambda}^{1} w(r) d r\right](w(1)-w(\lambda))\right\}= \\
= & \left(K_{1}^{\prime} M_{2} K_{1}\right)^{-1 / 2}[D E(\lambda)]^{-1}[N U(\lambda)] \\
\text { with }: & \\
{[N U(\lambda)]=} & \int_{0}^{1} w(r) d w(r)-\lambda^{-1}\left[\int_{0}^{\lambda} w(r) d r\right] w(\lambda)- \\
& -(1-\lambda)^{-1}\left[\int_{\lambda}^{1} w(r) d r\right](w(1)-w(\lambda))
\end{aligned}
$$

note also that:

$$
\left(Y_{N}^{-1} Q_{\theta} Y_{N}^{-1}\right)^{11} \Rightarrow\left(K^{\prime} K\right)^{11}[D E]^{-1}=\left(K_{1}^{\prime} M_{2} K_{1}\right)^{-1}[D E(\lambda)]^{-1}
$$

Then finally substituting (39) and (40) into (3) the required result is easily obtained. 


\section{B Tables}

Table 1.a

Empirical quantiles of $L R_{i o}$.

\begin{tabular}{rrrrr}
\hline$\lambda$ & 0.9 & 0.95 & 0.975 & 0.99 \\
\hline 0.2 & 8.5077 & 10.3599 & 12.1984 & 14.3974 \\
0.3 & 9.0153 & 10.8519 & 12.5488 & 14.8566 \\
0.4 & 9.3382 & 11.1417 & 12.9004 & 14.9936 \\
0.5 & 9.3446 & 11.1893 & 12.9652 & 15.3002 \\
0.6 & 9.3315 & 11.3013 & 13.0715 & 15.4670 \\
0.7 & 8.9711 & 10.9550 & 12.7243 & 14.7483 \\
0.8 & 8.4180 & 10.3099 & 12.1546 & 14.5669 \\
\hline
\end{tabular}

Table 1.b

Empirical size and power of $L R_{i o}$ for (15) with $i$ ).

\begin{tabular}{|c|c|c|c|c|c|c|c|c|c|c|c|}
\hline & & \multicolumn{5}{|c|}{$N=50$} & \multicolumn{5}{|c|}{$N=100$} \\
\hline$\prod_{s=1}^{4} \varphi_{s}$ & $\lambda$ & $P A R(1)$ & $P A R(2)$ & $P A R(3)$ & $P A R(4)$ & $P A R(5)$ & $P A R(1)$ & $P A R(2)$ & $P A R(3)$ & $P A R(4)$ & $P A R(5)$ \\
\hline 1 & 0.2 & 0.037 & 0.036 & 0.040 & 0.046 & 0.041 & 0.043 & 0.048 & 0.047 & 0.046 & 0.047 \\
\hline 1 & 0.4 & 0.036 & 0.038 & 0.038 & 0.043 & 0.049 & 0.044 & 0.044 & 0.048 & 0.046 & 0.046 \\
\hline 1 & 0.5 & 0.036 & 0.037 & 0.038 & 0.038 & 0.040 & 0.042 & 0.045 & 0.044 & 0.047 & 0.045 \\
\hline 1 & 0.6 & 0.035 & 0.038 & 0.036 & 0.041 & 0.045 & 0.044 & 0.045 & 0.043 & 0.046 & 0.041 \\
\hline 0.8 & 0.2 & 0.229 & 0.233 & 0.243 & 0.239 & 0.205 & 0.784 & 0.762 & 0.743 & 0.734 & 0.683 \\
\hline 0.8 & 0.3 & 0.205 & 0.209 & 0.213 & 0.221 & 0.185 & 0.730 & 0.715 & 0.691 & 0.679 & 0.633 \\
\hline 0.8 & 0.4 & 0.193 & 0.201 & 0.202 & 0.203 & 0.180 & 0.710 & 0.692 & 0.683 & 0.667 & 0.619 \\
\hline 0.8 & 0.5 & 0.177 & 0.189 & 0.187 & 0.194 & 0.169 & 0.696 & 0.677 & 0.657 & 0.637 & 0.595 \\
\hline 0.8 & 0.6 & 0.178 & 0.187 & 0.195 & 0.195 & 0.166 & 0.694 & 0.674 & 0.654 & 0.637 & 0.591 \\
\hline 0.5 & 0.4 & 0.951 & 0.908 & 0.858 & 0.798 & 0.709 & 1.000 & 1.000 & 1.000 & 1.000 & 0.999 \\
\hline 0.5 & 0.5 & 0.947 & 0.903 & 0.847 & 0.787 & 0.694 & 1.000 & 1.000 & 1.000 & 1.000 & 0.999 \\
\hline 0.5 & 0.6 & 0.950 & 0.908 & 0.861 & 0.793 & 0.710 & 1.000 & 1.000 & 1.000 & 1.000 & 1.000 \\
\hline 0.5 & 0.7 & 0.959 & 0.921 & 0.864 & 0.806 & 0.714 & 1.000 & 1.000 & 1.000 & 1.000 & 1.000 \\
\hline 0.5 & 0.8 & 0.968 & 0.932 & 0.892 & 0.830 & 0.738 & 1.000 & 1.000 & 1.000 & 1.000 & 1.000 \\
\hline
\end{tabular}


Table 1.c

Empirical size and power of $L R_{i o}$ for (15) with $\left.i i\right)$.

\begin{tabular}{|c|c|c|c|c|c|c|c|c|c|c|c|}
\hline & & \multicolumn{5}{|c|}{$N=50$} & \multicolumn{5}{|c|}{$N=100$} \\
\hline${ }_{s=1}^{4} \varphi_{s}$ & $\lambda$ & $P A R(1)$ & $P A R(2)$ & $P A R(3)$ & $P A R(4)$ & $P A R(5)$ & $P A R(1)$ & $P A R(2)$ & $P A R(3)$ & $P A R(4)$ & $P A R(5)$ \\
\hline 1 & 0.2 & 0.611 & 0.206 & 0.099 & 0.074 & 0.050 & 0.654 & 0.255 & 0.125 & 0.086 & 0.063 \\
\hline 1 & 0.3 & 0.651 & 0.215 & 0.093 & 0.068 & 0.052 & 0.685 & 0.247 & 0.113 & 0.085 & 0.067 \\
\hline 1 & 0.4 & 0.671 & 0.201 & 0.083 & 0.062 & 0.046 & 0.714 & 0.251 & 0.117 & 0.080 & 0.060 \\
\hline 1 & 0.5 & 0.684 & 0.199 & 0.084 & 0.057 & 0.040 & 0.718 & 0.250 & 0.113 & 0.079 & 0.061 \\
\hline 1 & 0.6 & 0.660 & 0.199 & 0.082 & 0.058 & 0.045 & 0.707 & 0.258 & 0.114 & 0.079 & 0.057 \\
\hline 1 & 0.7 & 0.635 & 0.191 & 0.084 & 0.055 & 0.041 & 0.674 & 0.239 & 0.111 & 0.073 & 0.054 \\
\hline 1 & 0.8 & 0.585 & 0.179 & 0.081 & 0.051 & 0.032 & 0.652 & 0.239 & 0.104 & 0.071 & 0.053 \\
\hline 0.8 & 0.2 & 0.997 & 0.766 & 0.482 & 0.366 & 0.278 & 1.000 & 0.998 & 0.956 & 0.887 & 0.789 \\
\hline 0.8 & 0.3 & 0.995 & 0.750 & 0.451 & 0.338 & 0.247 & 1.000 & 0.996 & 0.930 & 0.839 & 0.738 \\
\hline 0.8 & 0.4 & 0.996 & 0.729 & 0.431 & 0.314 & 0.242 & 1.000 & 0.996 & 0.927 & 0.828 & 0.723 \\
\hline 0.8 & 0.5 & 0.995 & 0.718 & 0.416 & 0.293 & 0.217 & 1.000 & 0.996 & 0.924 & 0.827 & 0.707 \\
\hline 0.8 & 0.6 & 0.996 & 0.730 & 0.419 & 0.296 & 0.218 & 1.000 & 0.997 & 0.948 & 0.871 & 0.782 \\
\hline 0.8 & 0.7 & 0.996 & 0.724 & 0.424 & 0.298 & 0.218 & 1.000 & 0.997 & 0.932 & 0.848 & 0.740 \\
\hline 0.5 & 0.2 & 1.000 & 1.000 & 0.987 & 0.943 & 0.868 & 1.000 & 1.000 & 1.000 & 1.000 & 1.000 \\
\hline 0.5 & 0.3 & 1.000 & 1.000 & 0.979 & 0.926 & 0.826 & 1.000 & 1.000 & 1.000 & 1.000 & 1.000 \\
\hline 0.5 & 0.4 & 1.000 & 1.000 & 0.975 & 0.921 & 0.819 & 1.000 & 1.000 & 1.000 & 1.000 & 1.000 \\
\hline 0.5 & 0.5 & 1.000 & 0.999 & 0.974 & 0.912 & 0.805 & 1.000 & 1.000 & 1.000 & 1.000 & 1.000 \\
\hline 0.5 & 0.6 & 1.000 & 1.000 & 0.976 & 0.910 & 0.810 & 1.000 & 1.000 & 1.000 & 1.000 & 1.000 \\
\hline 0.5 & 0.7 & 1.000 & 0.999 & 0.977 & 0.908 & 0.806 & 1.000 & 1.000 & 1.000 & 1.000 & 1.000 \\
\hline 0.5 & 0.8 & 1.000 & 1.000 & 0.985 & 0.930 & 0.840 & 1.000 & 1.000 & 1.000 & 1.000 & 1.000 \\
\hline
\end{tabular}


Table 1.d

Empirical size and power of $L R_{i o}$ for (15) with $i i i$ ).

\begin{tabular}{|c|c|c|c|c|c|c|c|c|c|c|c|}
\hline & & \multicolumn{5}{|c|}{$N=50$} & \multicolumn{5}{|c|}{$N=100$} \\
\hline$\varphi_{s}$ & $\lambda$ & $P A R(1)$ & $P A R(2)$ & $P A R(3)$ & $P A R(4)$ & $P A R(5)$ & $P A R(1)$ & $P A R(2)$ & $P A R(3)$ & $P A R(4)$ & $P A R(5)$ \\
\hline 1 & 0.2 & 0.016 & 0.043 & 0.053 & 0.070 & 0.155 & 0.022 & 0.051 & 0.074 & 0.108 & 0.218 \\
\hline 1 & 0.4 & 0.019 & 0.040 & 0.054 & 0.067 & 0.144 & 0.022 & 0.042 & 0.057 & 0.085 & 0.182 \\
\hline 1 & 0.5 & 0.023 & 0.043 & 0.052 & 0.065 & 0.139 & 0.023 & 0.042 & 0.058 & 0.087 & 0.189 \\
\hline 1 & 0.6 & 0.018 & 0.043 & 0.052 & 0.064 & 0.141 & 0.022 & 0.044 & 0.057 & 0.082 & 0.180 \\
\hline 0.8 & 0.2 & 0.003 & 0.229 & 0.229 & 0.217 & 0.203 & 0.010 & 0.721 & 0.708 & 0.681 & 0.643 \\
\hline 0.8 & 0.3 & 0.002 & 0.208 & 0.214 & 0.202 & 0.187 & 0.005 & 0.683 & 0.657 & 0.629 & 0.589 \\
\hline 0.8 & 0.4 & 0.002 & 0.199 & 0.201 & 0.190 & 0.172 & 0.004 & 0.640 & 0.620 & 0.598 & 0.561 \\
\hline 0.8 & 0.5 & 0.003 & 0.196 & 0.194 & 0.189 & 0.170 & 0.004 & 0.634 & 0.611 & 0.589 & 0.555 \\
\hline 0.8 & 0.6 & 0.002 & 0.185 & 0.187 & 0.174 & 0.165 & 0.003 & 0.634 & 0.613 & 0.591 & 0.562 \\
\hline 0.5 & 0.4 & 0.040 & 0.829 & 0.781 & 0.717 & 0.633 & 0.679 & 1.000 & 1.000 & 0.998 & 0.997 \\
\hline 0.5 & 0.5 & 0.038 & 0.822 & 0.770 & 0.707 & 0.621 & 0.674 & 1.000 & 1.000 & 0.999 & 0.997 \\
\hline 0.5 & 0.6 & 0.041 & 0.837 & 0.780 & 0.703 & 0.632 & 0.679 & 1.000 & 1.000 & 0.999 & 0.997 \\
\hline 0.5 & 0.7 & 0.048 & 0.829 & 0.776 & 0.707 & 0.633 & 0.715 & 1.000 & 1.000 & 0.999 & 0.997 \\
\hline 0.5 & 0.8 & 0.065 & 0.863 & 0.814 & 0.743 & 0.660 & 0.813 & 1.000 & 1.000 & 1.000 & 0.999 \\
\hline
\end{tabular}


Table 1.e

Empirical size and power of $L R_{i o}$ for (17) with $i$ ).

\begin{tabular}{|c|c|c|c|c|c|c|c|c|c|c|c|}
\hline & & \multicolumn{5}{|c|}{$N=50$} & \multicolumn{5}{|c|}{$N=100$} \\
\hline$\varphi_{s}$ & $\lambda$ & $P A R(1)$ & $P A R(2)$ & $P A R(3)$ & $P A R(4)$ & $P A R(5)$ & $P A R(1)$ & $P A R(2)$ & $P A R(3)$ & $P A R(4)$ & $P A R(5)$ \\
\hline 1 & 0.2 & 0.040 & 0.042 & 0.047 & 0.048 & 0.047 & 0.051 & 0.055 & 0.054 & 0.058 & 0.052 \\
\hline 1 & 0.4 & 0.040 & 0.038 & 0.036 & 0.042 & 0.049 & 0.046 & 0.045 & 0.049 & 0.050 & 0.048 \\
\hline 1 & 0.5 & 0.033 & 0.034 & 0.036 & 0.038 & 0.039 & 0.045 & 0.047 & 0.049 & 0.046 & 0.048 \\
\hline 1 & 0.6 & 0.038 & 0.040 & 0.039 & 0.042 & 0.036 & 0.043 & 0.043 & 0.046 & 0.050 & 0.048 \\
\hline 0.8 & 0.2 & 0.234 & 0.235 & 0.241 & 0.244 & 0.214 & 0.781 & 0.761 & 0.744 & 0.726 & 0.679 \\
\hline 0.8 & 0.3 & 0.208 & 0.208 & 0.217 & 0.218 & 0.189 & 0.718 & 0.706 & 0.687 & 0.669 & 0.619 \\
\hline 0.8 & 0.4 & 0.178 & 0.187 & 0.197 & 0.200 & 0.178 & 0.699 & 0.684 & 0.666 & 0.660 & 0.596 \\
\hline 0.8 & 0.5 & 0.183 & 0.191 & 0.187 & 0.193 & 0.172 & 0.700 & 0.667 & 0.654 & 0.639 & 0.592 \\
\hline 0.8 & 0.6 & 0.184 & 0.190 & 0.189 & 0.196 & 0.167 & 0.689 & 0.670 & 0.653 & 0.640 & 0.591 \\
\hline 0.5 & 0.4 & 0.951 & 0.908 & 0.862 & 0.803 & 0.713 & 1.000 & 1.000 & 1.000 & 1.000 & 1.000 \\
\hline 0.5 & 0.5 & 0.946 & 0.898 & 0.845 & 0.793 & 0.703 & 1.000 & 1.000 & 1.000 & 1.000 & 1.000 \\
\hline 0.5 & 0.6 & 0.944 & 0.897 & 0.852 & 0.805 & 0.713 & 1.000 & 1.000 & 1.000 & 1.000 & 0.999 \\
\hline 0.5 & 0.7 & 0.961 & 0.919 & 0.867 & 0.811 & 0.718 & 1.000 & 1.000 & 1.000 & 1.000 & 1.000 \\
\hline 0.5 & 0.8 & 0.975 & 0.941 & 0.900 & 0.842 & 0.751 & 1.000 & 1.000 & 1.000 & 1.000 & 1.000 \\
\hline
\end{tabular}


Table 1.f

Empirical size and power of $L R_{i o}$ for (17) with $\left.i i\right)$.

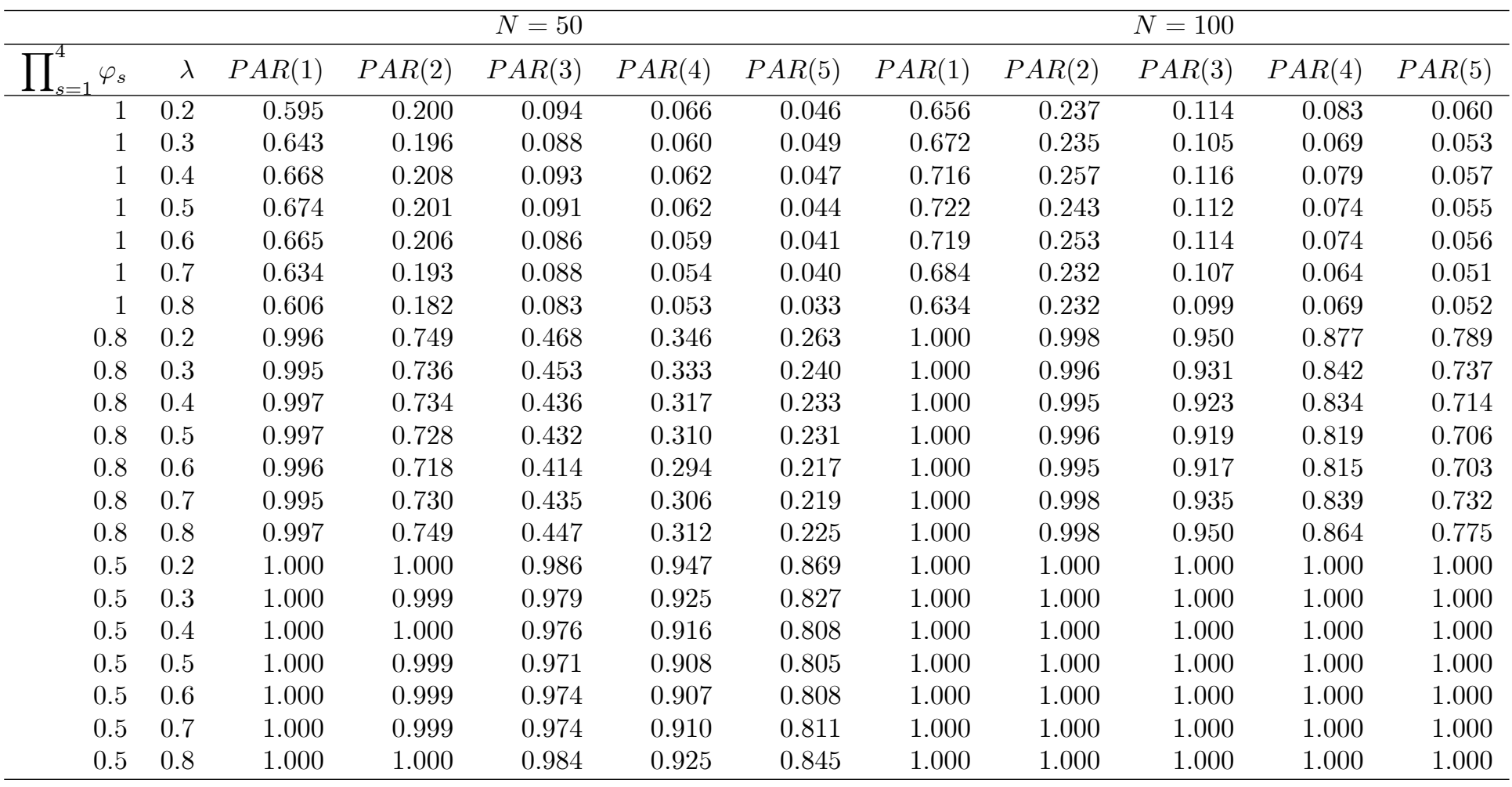


Table 1.g

Empirical size and power of $L R_{i o}$ for (17) with $\left.i i i\right)$. .

\begin{tabular}{|c|c|c|c|c|c|c|c|c|c|c|c|}
\hline & & \multicolumn{5}{|c|}{$N=50$} & \multicolumn{5}{|c|}{$N=100$} \\
\hline$\varphi_{s}$ & $\lambda$ & $P A R(1)$ & $P A R(2)$ & $P A R(3)$ & $P A R(4)$ & $P A R(5)$ & $P A R(1)$ & $P A R(2)$ & $P A R(3)$ & $P A R(4)$ & $P A R(5)$ \\
\hline 1 & 0.2 & 0.017 & 0.043 & 0.053 & 0.069 & 0.156 & 0.025 & 0.051 & 0.070 & 0.109 & 0.220 \\
\hline 1 & 0.4 & 0.020 & 0.041 & 0.053 & 0.068 & 0.145 & 0.022 & 0.043 & 0.059 & 0.088 & 0.189 \\
\hline 1 & 0.5 & 0.018 & 0.041 & 0.046 & 0.061 & 0.137 & 0.024 & 0.045 & 0.065 & 0.099 & 0.190 \\
\hline 1 & 0.6 & 0.017 & 0.036 & 0.045 & 0.057 & 0.133 & 0.024 & 0.044 & 0.059 & 0.083 & 0.186 \\
\hline 0.8 & 0.2 & 0.004 & 0.235 & 0.239 & 0.234 & 0.212 & 0.010 & 0.718 & 0.705 & 0.680 & 0.643 \\
\hline 0.8 & 0.3 & 0.004 & 0.216 & 0.219 & 0.216 & 0.191 & 0.006 & 0.669 & 0.652 & 0.624 & 0.591 \\
\hline 0.8 & 0.4 & 0.002 & 0.199 & 0.200 & 0.188 & 0.170 & 0.004 & 0.639 & 0.614 & 0.592 & 0.554 \\
\hline 0.8 & 0.5 & 0.002 & 0.198 & 0.203 & 0.186 & 0.172 & 0.003 & 0.646 & 0.621 & 0.594 & 0.556 \\
\hline 0.8 & 0.6 & 0.001 & 0.199 & 0.203 & 0.193 & 0.172 & 0.003 & 0.636 & 0.626 & 0.590 & 0.555 \\
\hline 0.5 & 0.4 & 0.043 & 0.830 & 0.771 & 0.704 & 0.629 & 0.672 & 1.000 & 1.000 & 0.999 & 0.997 \\
\hline 0.5 & 0.5 & 0.038 & 0.819 & 0.753 & 0.696 & 0.613 & 0.683 & 1.000 & 1.000 & 0.999 & 0.998 \\
\hline 0.5 & 0.6 & 0.043 & 0.825 & 0.768 & 0.698 & 0.620 & 0.685 & 1.000 & 1.000 & 0.999 & 0.997 \\
\hline 0.5 & 0.7 & 0.046 & 0.841 & 0.792 & 0.721 & 0.645 & 0.729 & 1.000 & 1.000 & 0.999 & 0.998 \\
\hline 0.5 & 0.8 & 0.061 & 0.865 & 0.802 & 0.733 & 0.659 & 0.815 & 1.000 & 1.000 & 1.000 & 0.999 \\
\hline
\end{tabular}


Table 2

Results

\begin{tabular}{|c|c|c|c|c|c|c|c|}
\hline Spain & $F_{n e r}$ & $L R_{i \Omega}(\lambda)$ & $\hat{\varphi}_{1}$ & $\hat{\varphi}_{n}$ & $\hat{\varphi}_{2}$ & $\hat{\varphi}_{1}$ & $L R_{C R}$ \\
\hline $\exp / \operatorname{dgp}$ & 0.9876 & 4.6657 & 1.0179 & 1.0458 & 0.8912 & 1.0541 & $10.7291^{*}$ \\
\hline $\operatorname{imp} / \operatorname{dgp}$ & 0.3175 & $10.4385^{*}$ & 1.1197 & 1.0000 & 0.9222 & 0.9684 & \\
\hline $\ln (\exp / \operatorname{dgp})$ & 0.6198 & 6.7820 & 1.0758 & 1.0230 & 1.0063 & 0.9029 & $10.0310^{*}$ \\
\hline $\ln (\operatorname{imp} / \operatorname{dgp})$ & 0.6668 & $11.3004^{*}$ & 1.1777 & 1.0185 & 0.9377 & 0.8891 & \\
\hline France & $F_{p e r}$ & $L R_{i o}(\lambda)$ & $\hat{\varphi}_{1}$ & $\hat{\varphi}_{2}$ & $\hat{\varphi}_{3}$ & $\hat{\varphi}_{4}$ & $L R_{C R}$ \\
\hline $\exp / \operatorname{dgp}$ & 0.2956 & $13.7320^{* *}$ & - & - & - & - & - \\
\hline $\operatorname{imp} / \operatorname{dgp}$ & 1.3455 & $15.6965^{* *}$ & - & - & - & - & \\
\hline $\ln (\exp / \operatorname{dgp})$ & 0.1015 & $13.7380^{* *}$ & - & - & - & - & - \\
\hline $\ln (\operatorname{imp} / \operatorname{dgp})$ & 0.3885 & $13.9926^{* *}$ & - & - & - & - & \\
\hline Italy & $F_{\text {per }}$ & $L R_{i o}(\lambda)$ & $\hat{\varphi}_{1}$ & $\hat{\varphi}_{2}$ & $\hat{\varphi}_{3}$ & $\hat{\varphi}_{4}$ & $L R_{C R}$ \\
\hline $\exp / \operatorname{dgp}$ & $4.2104^{* * *}$ & 6.7669 & 1.3044 & 0.8821 & 0.8559 & 1.0154 & 4.2554 \\
\hline $\operatorname{imp} / \operatorname{dgp}$ & $6.7757^{* * *}$ & 8.7128 & 1.3155 & 0.8156 & 1.0204 & 0.9133 & \\
\hline $\ln (\exp / \operatorname{dg} p)$ & $2.2115^{*}$ & 8.4031 & 1.2584 & 0.9051 & 0.9147 & 0.9597 & 4.7141 \\
\hline $\ln (\mathrm{imp} / \operatorname{dgp})$ & $2.8290^{* *}$ & 8.9749 & 1.1412 & 0.9120 & 1.1247 & 0.8542 & \\
\hline Finland & $F_{\text {per }}$ & $L R_{i o}(\lambda)$ & $\hat{\varphi}_{1}$ & $\hat{\varphi}_{2}$ & $\hat{\varphi}_{3}$ & $\hat{\varphi}_{4}$ & $L R_{C R}$ \\
\hline $\exp / \operatorname{dgp}$ & $4.8178^{* * *}$ & 2.6434 & 1.1474 & 1.0408 & 0.7818 & 1.0710 & 3.9836 \\
\hline $\operatorname{imp} / \operatorname{dgp}$ & $3.1068^{* *}$ & $13.8461^{* *}$ & 1.0343 & 1.1032 & 1.1135 & 0.7871 & \\
\hline $\ln (\exp / \operatorname{dgp})$ & $3.2237^{* * *}$ & 4.1203 & 1.0739 & 1.1278 & 0.8534 & 0.9674 & $11.4335^{* *}$ \\
\hline $\ln (\operatorname{imp} / \operatorname{dg} p)$ & $2.0870^{*}$ & 6.9096 & 0.8141 & 1.2805 & 1.0485 & 0.9149 & \\
\hline Netherlands & $F_{p e r}$ & $L R_{i o}(\lambda)$ & $\hat{\varphi}_{1}$ & $\hat{\varphi}_{2}$ & $\hat{\varphi}_{3}$ & $\hat{\varphi}_{4}$ & $L R_{C R}$ \\
\hline $\exp / d g p$ & $6.1678^{* * *}$ & $12.7855^{* *}$ & 0.7902 & 1.3892 & 1.0735 & 0.8486 & 4.9678 \\
\hline $\operatorname{imp} / \operatorname{dgp}$ & $6.8509 * * *$ & 8.8625 & 1.2819 & 0.8674 & 0.9714 & 0.9258 & \\
\hline $\ln (\exp / \operatorname{dgp})$ & 1.1100 & $9.6861^{*}$ & 0.9155 & 0.9379 & 1.0309 & 1.1297 & $15.3403^{* *}$ \\
\hline $\ln (\operatorname{imp} / \operatorname{dg} p)$ & 0.3862 & $9.9918^{*}$ & 0.9482 & 0.9895 & 1.0688 & 0.9972 & \\
\hline
\end{tabular}




\section{Graphs}

Figure 1 Evolution of exp/gdp and imp/gdp for Spain.

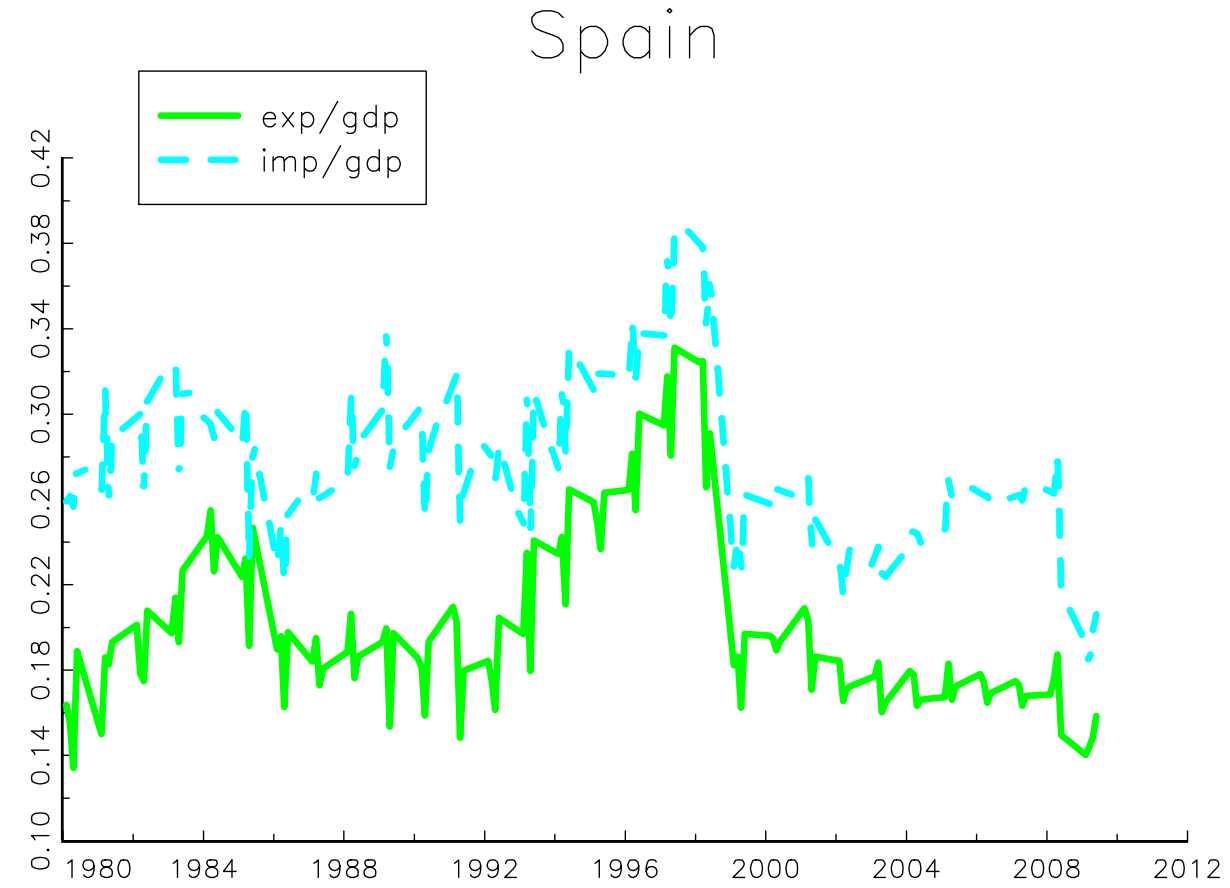

Figure 2 Evolution of exp/gdp and imp/gdp for Italy.

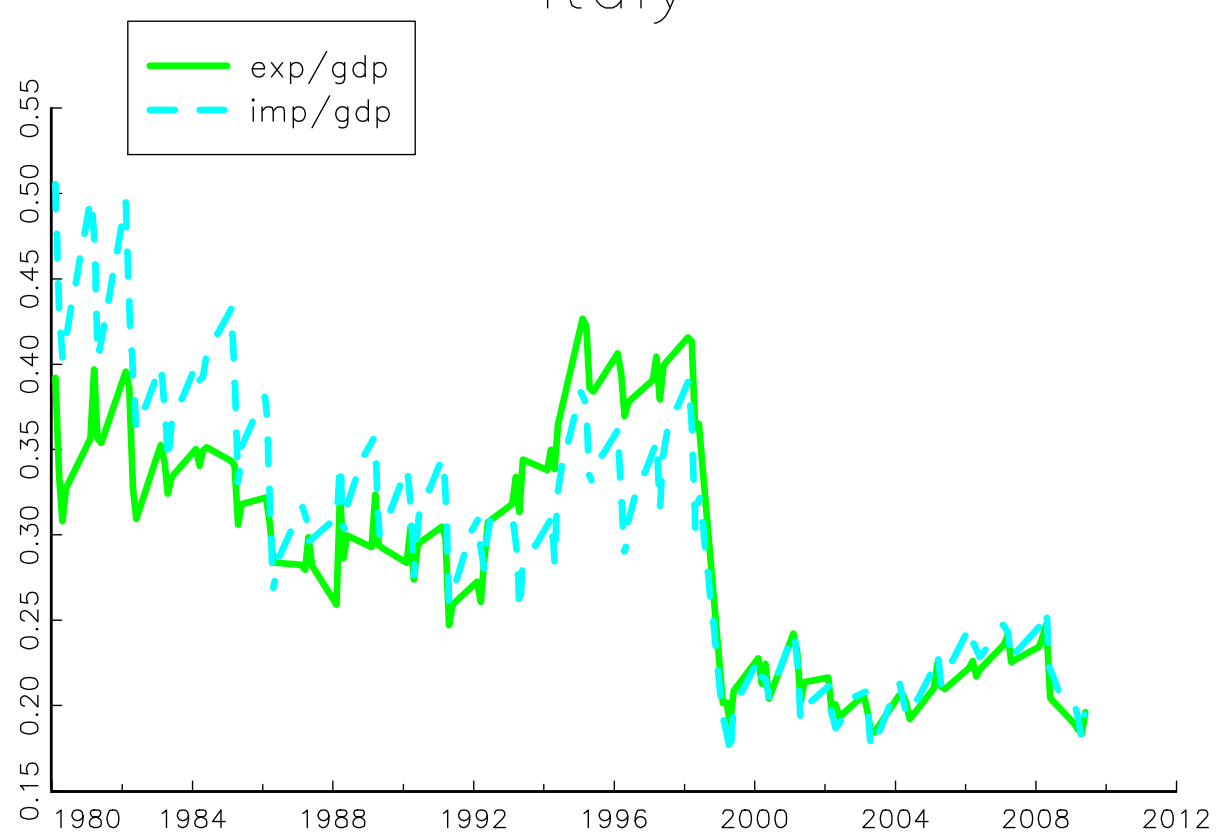


Figure 3 Evolution of exp/gdp and imp/gdp for Finland.

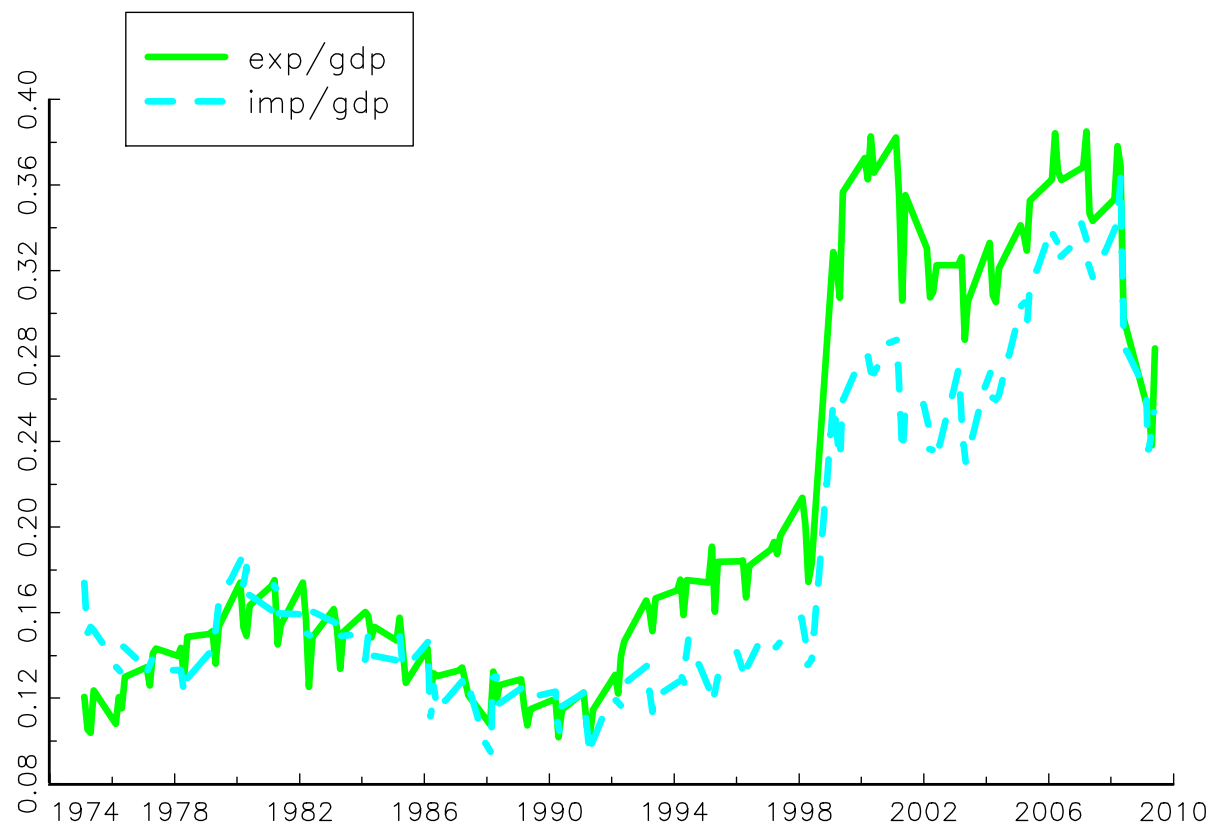

Figure 4 Evolution of exp/gdp and imp/gdp for The Netherlands.

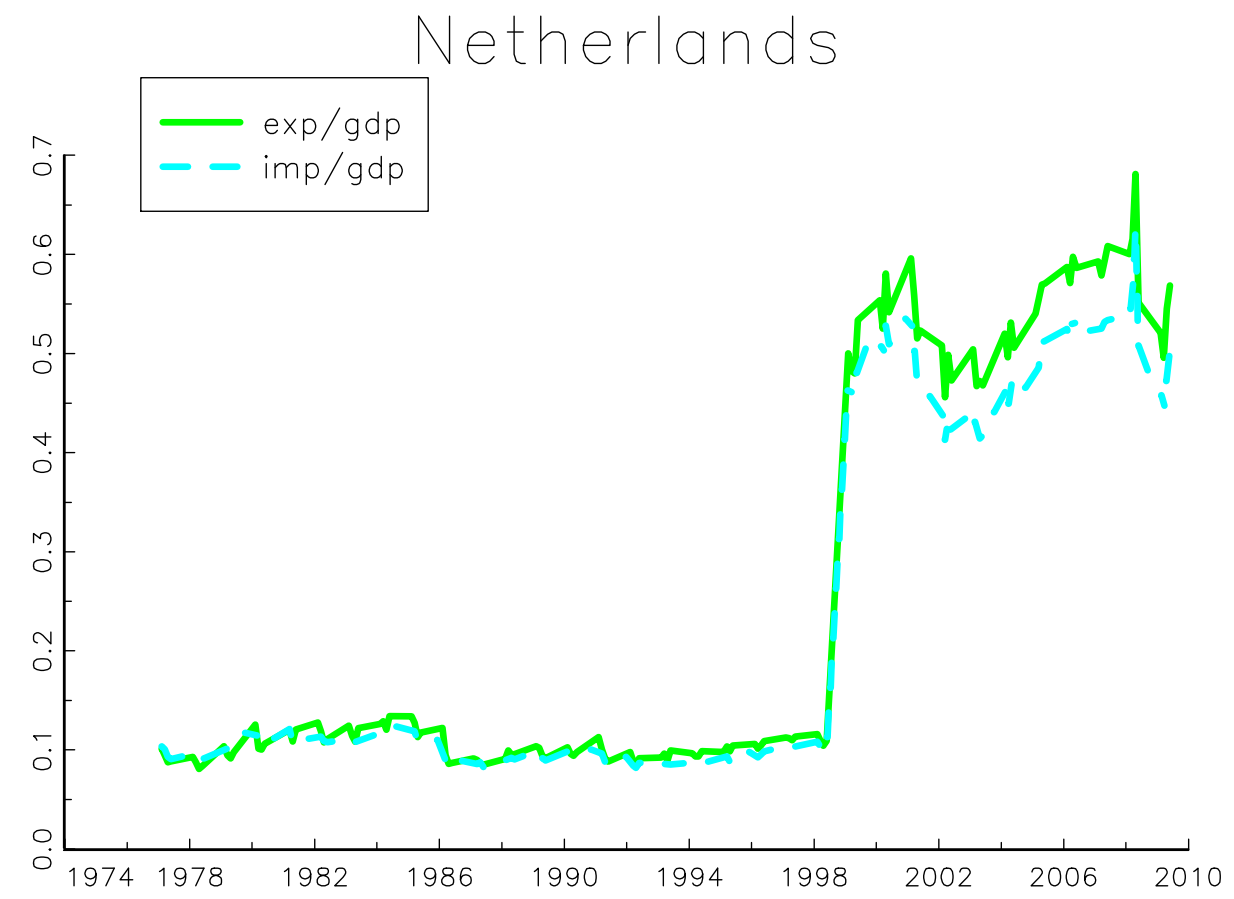


Figure 5 Evolution of exp/gdp and imp/gdp for France.

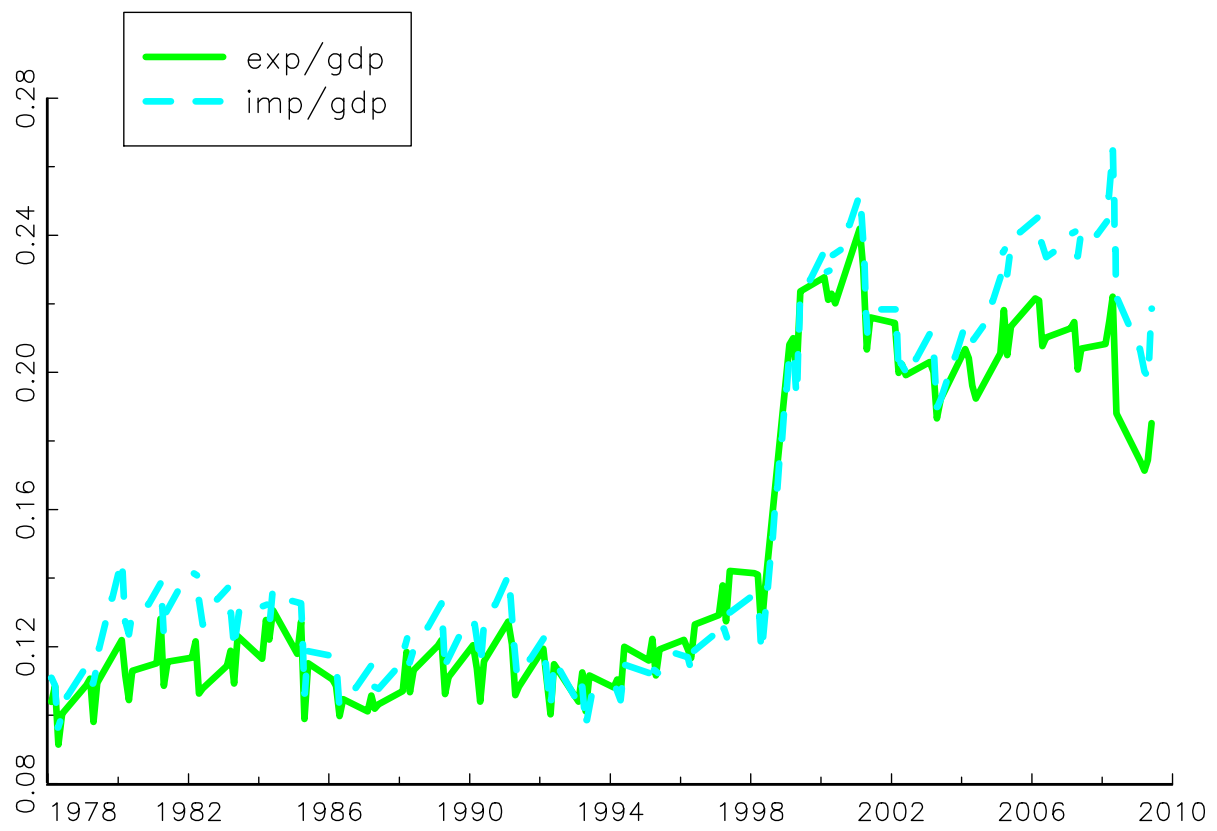




\section{Empirical literature}

\begin{tabular}{|c|c|c|c|c|}
\hline Authors & Countries analyzed & Period & Variables & Techniques \\
\hline Arize(2002) & 50 , all continents & quart., $73-98$ & nom. X/GDP, M/GDP dom. curr. & Johansen, SW, Hansen \\
\hline Fountas and Wu (1999) & US & quart., $67-94$ & $\mathrm{X}, \mathrm{M}$, real, nominal, relative & EG, structural breaks \\
\hline Greenidge et al. (2011) & Barbados & annu. $60-2006$ & real X/GDP, M/GDP & ERS, NP, KPSS, Johansen, DOLS \\
\hline Hamori $(2009)$ & G-7 countries & annu, $60-2005$ & $\mathrm{X}$ and $\mathrm{M}, \mathrm{mill}$. US $\$$, trade bal & panel u. roots, coint., IPS, Pedroni \\
\hline Herzer \& Nowak-L. (2006) & Chile & annu, $75-2004$ & real $\mathrm{X}$ and $\mathrm{M}$ domest. currency & Gregory-Hansen, D OLS, ECM \\
\hline Holmes et al (2011) & India & annu. 50-2003 & $\mathrm{X} / \mathrm{GDP}, \mathrm{M} / \mathrm{GDP}$ & $\begin{array}{l}\text { Johansen, Saikkonen \& Lütkepohl, } \\
\text { Breitung, Breitung and Taylor }\end{array}$ \\
\hline Husted (1992) & US & quart. $67-89$ & nom., real, differenced ratios & EG, ADF, Perron-breaks \\
\hline Irandoust and Sjoo (2000) & Sweden & quart. $80-95$ & nom., real, X, M/GDP dom. curr. & VECM, Johansen, stability tests \\
\hline Irandoust and Ericsson (2004) & $\mathrm{Fr}, \mathrm{G}, \mathrm{I}, \mathrm{Sw}, \mathrm{UK}, \mathrm{US}$ & quart. $71-97$ & real, log, seasonally adj. & VECM, Johansen, stability tests \\
\hline Nag and Mukherjee (2012) & India & annu. 50-2008 & real $\mathrm{X}$ and $\mathrm{M}$ (inclusive interest) & Lee and Strazicich, Gregory-Hansen \\
\hline Narayan and Narayan (2005) & 22 least developed & annu. $60-2000$ & nominal $X$ and $M$ & bounds ARDL, ECM, Hansen, DOLS \\
\hline
\end{tabular}

